\title{
Out with the old? The role of selective attention in retaining targets in partial report
}

\author{
Dakota R. B. Lindsey ${ }^{1}$ - Claus Bundesen ${ }^{2}$ - Søren Kyllingsbak ${ }^{2}$ - Anders Petersen ${ }^{2}$. \\ Gordon D. Logan ${ }^{1}$
}

Published online: 14 October 2016

(C) The Psychonomic Society, Inc. 2016

\begin{abstract}
In the partial-report task, subjects are asked to report only a portion of the items presented. Selective attention chooses which objects to represent in short-term memory (STM) on the basis of their relevance. Because STM is limited in capacity, one must sometimes choose which objects are removed from memory in light of new relevant information. We tested the hypothesis that the choices among newly presented information and old information in STM involve the same process - that both are acts of selective attention. We tested this hypothesis using a two-display partial-report procedure. In this procedure, subjects had to select and retain relevant letters (targets) from two sequentially presented displays. If selection in perception and retention in STM are the same process, then irrelevant letters (distractors) in the second display, which demanded attention because of their similarity to the targets, should have decreased target report from the first display. This effect was not obtained in any of four experiments. Thus, choosing objects to keep in STM is not the same process as choosing new objects to bring into STM.
\end{abstract}

Keywords Attention: Interactions with memory - Selective attention $\cdot$ Short-term memory

Dakota R. B. Lindsey

dakota.r.lindsey@vanderbilt.edu

1 Vanderbilt University, Nashville, TN, USA

2 University of Copenhagen, Copenhagen, Denmark
Every one knows what attention is. It is the taking possession by the mind, in clear and vivid form, of one out of what seem several simultaneously possible objects or trains of thought. Focalization, concentration, of consciousness are of its essence. (p. 403)

The physical condition in the nerve-tissue of this primary memory is called by Richet "elementary memory." I much prefer to reserve the word memory for the conscious phenomenon. (p. 646)

We cannot deny that an object once attended to will remain in the memory, whilst one inattentively allowed to pass will leave no traces behind. (p. 427)

William James, Principles of Psychology

The link between attention and memory is a topic that has piqued scientific interest for over a century. Long before scientists of the cognitive revolution dissected the concepts of attention and memory separately, William James (1890) spoke of their interaction. To James, attention and memory are linked through consciousness; short-term memory (STM) holds the contents of consciousness, while attention dictates what content becomes conscious. The objects we attend get into STM, and we become conscious of them. The objects we do not attend generally do not. This process, which allows one to filter out the environment in accordance with some goal, is known as selective attention (e.g., Broadbent, 1957; Lachter, Forster, \& Ruthruff, 2004).

Selective attention is often conceptualized as a choice of objects out in the world - it acts on perceptual representations of the environment (Bundesen, 1990, 1998; Logan, 1996; Nosofsky, 1986). Recent research on working memory has suggested that selective attention may have a more complex role in cognition. Awh and Jonides (2001) found that selecting spatial locations affected the rehearsal of spatial locations stored in visual STM. Similarly, Kiyonaga and Egner 
(2014a, 2014b) claimed that a common resource is used to select items in perception and maintain items in STM. Kiyonaga and Egner (2013) also described working memory as attention directed toward memory rather than toward perceptual representations (see also Baddeley, 1993; Engle, 2002; Oberauer \& Lewandowsky, 2011). ${ }^{1}$ These claims point to the possibility of a single selective-attention mechanism that operates within STM as well as perception.

We assume that selective attention chooses the perceptual objects to represent in STM. We additionally assume that selection involves a processing race between objects (Bundesen, 1990). The objects in the display compete to be selected into STM. Attention biases certain objects to be processed faster than others, and the objects that finish processing first are encoded into STM. We tested the hypothesis that selective attention also chooses which objects to retain in STM once they are there. The objects in STM compete in the race with perceptual objects. If they are reselected, they are retained; otherwise, they are forgotten. Thus, when new objects are presented and must be selected, the objects in STM are jeopardized.

We assume that there is no limit to the number of objects a person can attend at once. However, the likelihood that an object is selected into STM depends on how much attention it receives, relative to all of the objects being attended (i.e., the relative attention weight of the object; Bundesen, 1990). Because the relative attention weight of an object dictates the likelihood of selection, adding more objects to the race increases the amount of competition and decreases the likelihood that any particular object will be selected. Objects that are salient, because of either their visual quality or their importance to the task, are more likely to be selected and make less salient objects less likely to be selected.

Our experiments involved a modified partial-report task. In the typical partial-report task, a display of letters is presented to subjects, and they are asked to report only a subset of the items. A cue informs the subjects which letters they should report, and the cue can be given either after (e.g., Sperling, 1960) or before (e.g., Eriksen \& Collins, 1969; Shibuya \& Bundesen, 1988) display presentation. The letters that subjects are supposed to attend are called targets, and the letters they are supposed to ignore are called distractors. When the distractors are similar in appearance to the targets, the selection of targets is more difficult. A typical finding is that target report decreases as the number of distractors in the display increases (Bundesen, Pedersen, \& Larsen, 1984; Bundesen, Shibuya, \& Larsen, 1985; Shibuya \& Bundesen, 1988). This is an attentional effect on perception - the distractors compete with the targets for

\footnotetext{
${ }^{1}$ In this article, we prefer to use the term "short-term memory" rather than "working memory." We treat the system as a passive buffer that holds objects, and assume that selective attention is the process doing the "work." The working memory system comprises the STM buffer and the attentional processes that act on the objects within it, such as selective attention (Baddeley \& Hitch, 1974; Engle, 2002).
}

selection, so the magnitude of their impact is indicative of the efficiency of selection (Bundesen et al., 1984).

The traditional partial-report task would not allow us to analyze the competition between the objects in memory and perception because the targets in memory are recalled immediately after selection. We created such a competition by presenting a second display of letters after the offset of the first. Subjects were asked to remember targets from both displays, so they had to select and retain targets from each. Critically, we could now see how the number of distractors presented in the second display would affect retention of the targets from the first display. The distractors in the second display were supposed to be ignored, so they demanded selective attention but not space in memory. If selection in perception and retention in STM involve the same process, then distractors in perception should compete directly with the targets in memory for selective attention. ${ }^{2}$ The second-display distractors should then reduce first-display target report.

\section{Overview of experiments}

We conducted four experiments. The first was intended to establish the effect of interest: Do second-display distractors affect first-display target report? In Experiment 1, this effect was not obtained. We were concerned that the distractors were too easily filtered or the objects in memory had been verbally recoded. In Experiment 2, we made the distractors more similar to the targets to increase their demand for selective attention. We then attempted to remove verbal coding, by using articulatory suppression in Experiment 3 and spatially oriented stimuli in Experiment 4. Each of these experiments was consistent with the first: Second-display distractors did not affect first-display target report. Our findings thus suggest that choosing objects to keep in memory and choosing new objects to bring into memory are different processes.

\section{Experiment 1: Two-display partial report}

In the first experiment, we investigated the effect of distractors on target report. We manipulated the number of target letters

\footnotetext{
${ }^{2}$ The degree of competition between targets in STM and distractors in perception will depend on how confusable the objects in STM and perception are. If objects in STM are represented differently from objects in perception, then they would be easily distinguished by selective attention, and little competition should occur. Pratte and Tong (2014) showed that objects maintained in visual working memory produced activity in early visual areas similar to that from perceiving the same object. We thus assume that objects held in STM are represented similarly to objects in perception. Targets held in STM should thus compete with distractors in perception similarly to how perceptual targets and perceptual distractors compete. Our assumption relies on the objects in STM not being verbally recoded, since they would then lose their visual representation and be much less confusable with perceptual objects.
} 
and distractor letters that were presented in each display and analyzed their effects on target report. If objects in memory and objects in perception compete for selective attention, then increasing the number of distractors in the second display should reduce first-display target report.

\section{Method}

Subjects We recruited 24 subjects in the Nashville area for Experiment 1. All of the subjects were between the ages of 18 and 35 , reported normal or corrected-to-normal vision, and reported no color blindness. The subjects were tested for $1.5 \mathrm{~h}$ and were compensated $\$ 18$ for their time.

Apparatus and stimuli The stimuli were presented on cathode ray tube displays, and responses were taken from the computer keyboard. The letters were limited to 14 from the alphabet: C, D, F, H, J, K, L, N, Q, R, S, V, W, and Z, all capitalized. They were rendered in either black, $\operatorname{RGB}(0,0,0)$, or gray, RGB $(150,150,150)$. The background of the display was white, RGB $(255,255,255)$.

In each array, from zero to four target letters could appear with one to three distractor letters. On some trials no targets were present, but at least one distractor was presented in each display on every trial. Letters were selected into the arrays randomly without replacement, so that each letter could appear at most once during each trial. The letters were randomly assigned to positions in $4 \times 4$ matrices. Each matrix measured $53 \times 53 \mathrm{~mm}$. The cells in the matrix were $13.25 \times 13.25 \mathrm{~mm}$ apiece, and the letters encompassed the middle $6.62 \mathrm{~mm} \times 6.62 \mathrm{~mm}$ of each cell. The positions in the matrix did not repeat within a trial, and the matrix itself was not visible to the subjects.

Procedure At the beginning of the experiment, prior to doing any trials, subjects were informed of which letters were targets and which were distractors. For half (12) of the subjects, the target letters were black and the distractor letters were gray. For the other half, the target and distractor colors were swapped. The subjects were asked to remember the target letters and ignore the distractors. They were informed that they would have to type the target letters at the end of each trial. Subjects were told not to type any letters if no targets were presented in a trial.

Each trial began with a "Get Ready" signal presented in the center of the screen for $500 \mathrm{~ms}$. A fixation cross was then presented in the center of the screen, also for $500 \mathrm{~ms}$. The fixation cross was removed, and an array of one to seven letters was presented on screen for $100 \mathrm{~ms}$. The array was then removed and a blank screen was shown for $1 \mathrm{~s}$. A second array of one to seven letters was then presented on screen for 100 ms. Figure 1 shows an example of two displays that could have appeared in a trial.

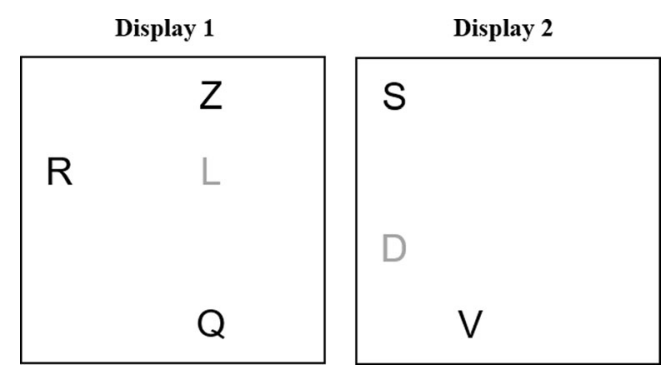

Fig. 1 Examples of two displays of letters that could have been presented in Experiment 1. Note that the letter identities and letter locations do not repeat

Once the second array was removed, the subject was prompted to type the target letters with a "Response" signal in the center of the screen. The subject's keystrokes were echoed on the screen. Also, only the letter keys were enabled; the backspace key was disabled, so subjects were not allowed to correct their responses. Subjects submitted their responses by pressing the Enter key, which cleared the screen and began the next trial. Five blocks of 90 trials were presented, for a total of 450 experimental trials. Subjects were allowed short breaks after each block of trials. Before doing the first block of experimental trials, the subjects completed ten practice trials which were identical in procedure to the experimental trials.

\section{Results and discussion}

We calculated descriptive statistics for the numbers of targets and distractors reported from each display as a function of the numbers of targets and distractors presented in each display. These statistics are shown in Table 1 in the appendices. Two 5 (first-display targets) $\times 3$ (first-display distractors) $\times 5$ (second-display targets) $\times 3$ (second-display distractors) within-subjects analyses of variance (ANOVAs) were run on the data to analyze target report from each of the two displays. The ANOVA effects are shown in Table 2 in the appendices. Our discussion focuses specifically on how target report is affected by the number of distractors presented.

We calculated Bayes factors (BF) with the assistance of JASP (JASP Team, 2016) and present them for the effects discussed. The BF for a main effect was obtained by comparing the model containing all main effects (the alternative or full model) with the model containing all main effects but the effect of interest (the null or reduced model). If the BF favors the alternative hypothesis, it is followed by an "(A)"; if it favors the null, it is followed by an " $(\mathrm{N})$."

The analysis revealed competition among the targets from the two displays for representation in STM. The number of firstdisplay targets reported decreased with the number of seconddisplay targets presented, $F(4,92)=12.40, p<.001, \mathrm{BF}=$ $4,184,927$ (A). Likewise, second-display target report decreased with the number of first-display targets presented, $F(4,92)=$ 
$74.76, p<.001, \mathrm{BF}=1.15 \times 10^{103}$ (A). Having to remember more first-display targets made remembering second-display targets more difficult, and vice versa. The results do not specify the nature of the competition among the targets; it could be a competition for selective attention or for space in STM, because the targets demanded both. ${ }^{3}$ The effect of distractors specifies the nature of the competition more directly.

The number of distractors in each display affected target report in its respective display, but the effect was only significant for the second display, $F(2,46)=8.29, p<.001, \mathrm{BF}=$ 4.14 (A), for the second display, and $F(2,46)=2.88, p>.05$, $\mathrm{BF}=5.47(\mathrm{~N})$, for the first display. Figure 2 shows these effects, focusing specifically on trials in which four targets were presented because we were interested in attentional effects that would occur when the targets demanded all of the subjects' STM capacity (which is generally thought to be around four objects; Cowan, 2010; Luck \& Vogel, 1997; Sperling, 1960; Vogel, Woodman, \& Luck, 2001). Distractors had similar effects in each display: In each case, they reduced the numbers of targets reported.

The first-display results are somewhat troubling, because they suggest that the targets and distractors in the first display did not compete for selective attention. However, the effects in the two displays were very similar. The inconsistency in the significance of this effect may have occurred because discrimination between the targets and distractors was too easy. Despite this inconsistency, it is important that the effect of distractors was significant in the second display. A significant effect of distractors on second-display target report was necessary to allow for any meaningful conclusions about their effect on first-display target report.

Second-display distractors did not affect first-display target report, even though they reduced second-display target report. The effect of the second-display distractors on first-display target report was not significant, $F(2,46)=1.18, p>.05$, $\mathrm{BF}=200.14(\mathrm{~N})$. Figure 3 shows the effects of the second-

\footnotetext{
${ }^{3}$ The targets from the second display could reduce first-display target report in two ways. Second-display targets could pull attention away from first-display targets in STM, making the first-display targets less likely to be reselected (and thus making them lose their place in STM). Alternatively, second-display targets, once selected, could displace the first-display targets in STM because the capacity of STM is limited. The competition for attention would lend support to our hypothesis, but the current experimental paradigm did not allow us to isolate it from the competition for STM space. We attempted to isolate the competition for attention between STM targets and perceptual targets with an experiment that was structured identically to Experiment 1 but that required subjects to enumerate the targets in the second display rather than report their identities. Enumeration requires selectively attending the targets, but the result is a single digit stored in STM. Thus, the targets and distractors in the second display would require attention, but not space in memory. In this experiment, neither the targets nor the distractors in the second display affected the first-display targets held in STM; there was no evidence of a competition for attention between objects in STM and objects in perception.
}

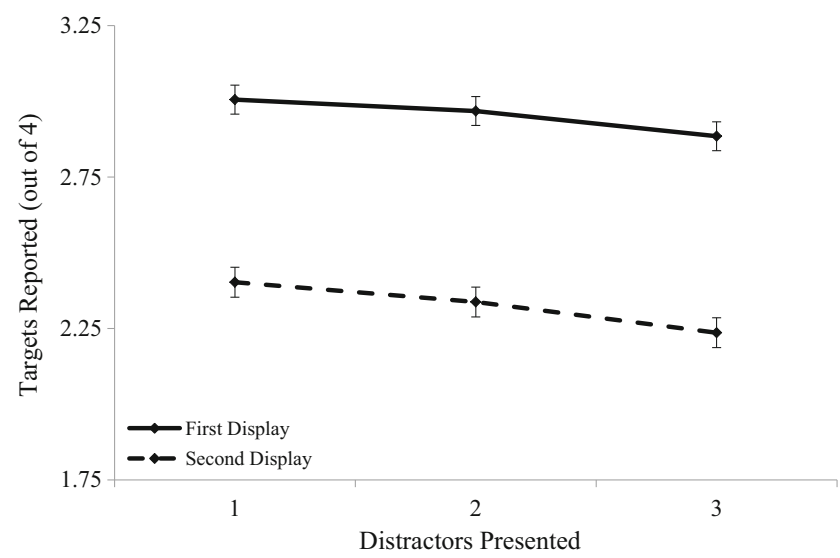

Fig. 2 Experiment 1: Mean numbers of targets reported in each display as a function of the number of distractors in that display. The solid line shows the numbers of targets reported from the first display when 4 targets were presented in the first display, and the dashed line shows the numbers of targets reported from the second display when 4 targets were presented in the second display. Error bars show Fisher's least significant differences for $p<.05$, calculated using the mean squared error and the degrees of freedom for the corresponding ANOVA interaction effect

display distractors when four targets were presented in the first display.

If retention in memory and selection in perception are the same process, then objects in memory and objects in perception should compete for selective attention. We found no such competition in Experiment 1, where second-display distractors did not impact report of the first-display targets being held in memory. Thus, selection in perception and retention in STM may involve different processes. However, this conclusion is limited because the distractors demanded little attention in the first display. Demanding distractors should have reduced the target reports in both displays.

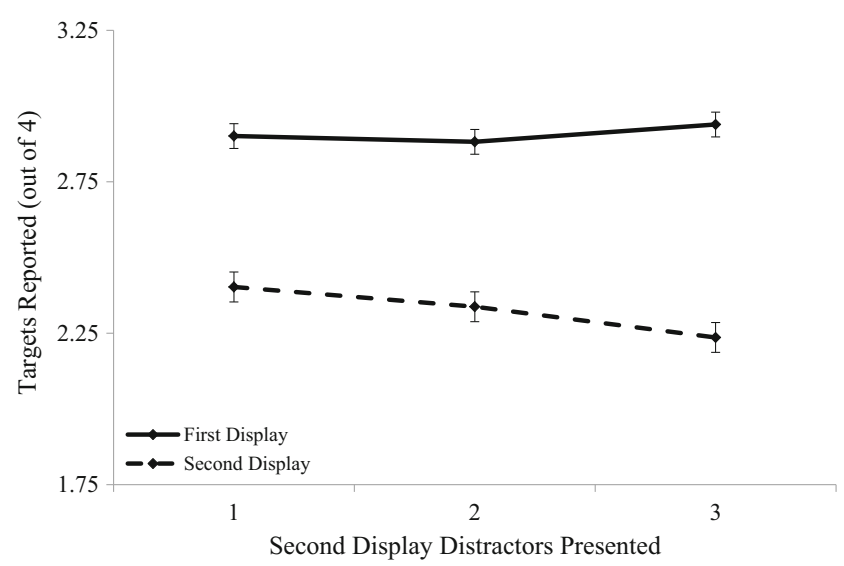

Fig. 3 Experiment 1: Mean numbers of targets reported from the first (solid line) and second (dashed line) displays as a function of the number of distractors presented in the second display. The results are shown for trials in which four targets were presented in each display. Error bars show Fisher's least significant differences for $p<.05$, calculated using the mean squared error and the degrees of freedom for the corresponding ANOVA interaction effect 


\section{Experiment 2: Two-display partial report with more difficult discrimination}

In Experiment 2, we made the distractors more similar to the targets to increase their demand for selective attention, by darkening the shade of gray to decrease the contrast between the targets and distractors. We were also concerned that the subjects might verbally recode the letter stimuli. We asked the subjects to report their strategies at the end of the experiment to see whether this was plausible.

\section{Method}

Subjects We recruited 24 subjects from the Nashville area for Experiment 2. All were between the ages of 18 and 35, reported normal or corrected-to-normal vision, reported no color blindness, and had not participated in Experiment 1. The subjects were tested for $1.5 \mathrm{~h}$ and were compensated $\$ 18$ for their time.

Apparatus and stimuli The letters were limited to 16 from the alphabet: B, C, D, F, H, J, K, L, M, N, Q, R, S, V, W, and Z. Each array could feature one or four target letters and one or four distractor letters. Therefore, each array could contain two, five, or eight letters. The zero-, two-, and three-item conditions that had been present in Experiment 1 were removed to increase the number of four-target-per-display trials completed by the subjects in the allotted time. In Experiment 1, the gray color had been RGB $(150,150,150)$. In Experiment 2, the gray was changed to RGB $(100,100,100)$. The black color remained the same, $\operatorname{RGB}(0,0,0)$. All other aspects of the apparatus and stimuli were identical to those of Experiment 1.

Procedure Five blocks of 96 trials were presented, for a total 480 experimental trials. At the end of the experiment, subjects were asked to freely report any strategies they had used to help them remember the letters in the task. All other aspects of the procedure were identical to the procedures of Experiment 1.

\section{Results and discussion}

We calculated the mean numbers of targets and distractors reported in each display, and the effects of display composition on target and distractor report from each display were analyzed with a 2 (first-display targets) $\times 2$ (first-display distractors) $\times 2$ (second-display targets) $\times 2$ (second-display distractors) within-subjects ANOVA. The descriptive statistics and ANOVA effects are shown in Tables 3 and 4 in the appendices. Jeffrey-Zellner-Siow BFs were calculated (Rouder, Speckman, Sun, Morey, \& Iverson, 2009) and transformed into one-sided BFs using the Morey and Wagenmakers
(2014) approximation. These one-sided BFs are presented for the discussed effects.

We again observed competition among the targets for representation in STM. First-display target report decreased with the number of second-display targets presented, $F(1,23)=$ $5.81, p<.05, \mathrm{BF}=3.81(\mathrm{~A})$, and second-display target report decreased with the number of first-display targets presented, $F(1,23)=36.59, p<.001, \mathrm{BF}=12,117.74(\mathrm{~A})$. These results replicate our Experiment 1 findings. Again, this competition could be for selective attention or space within STM.

Distractors competed for selective attention within each display. The distractors in both the first display, $F(1,23)=4.97, p$ $<.05, \mathrm{BF}=2.73(\mathrm{~A})$, and the second, $F(1,23)=92.78, p<$ $.001, \mathrm{BF}=18,421,592(\mathrm{~A})$, reduced the target report within their respective displays. The within-display distractor effects are displayed in Fig. 4. The effect of distractors was slightly larger in the second display than in the first.

Critically, second-display distractors did not reduce firstdisplay target report, $F(1,23)=0.85, p>.05, \mathrm{BF}=11.58(\mathrm{~N})$. Figure 5 shows how second-display distractors affected firstdisplay target report when four targets had to be retained from the first display. Although the second-display distractors reduced target report from the second display, they had no effect on target report from the first. The lack of an effect of the second-display distractors on first-display target report cannot be explained by an easy discrimination process: Even when the distractors were made more difficult to filter, perceptual distraction did not affect the objects held in STM.

The post experiment interview revealed that 21 of the 24 subjects ( $87.5 \%$ of all subjects) had rehearsed the letters presented in the displays. The fact that subjects could and often did rehearse the letters clouds the interpretation of the null effect of

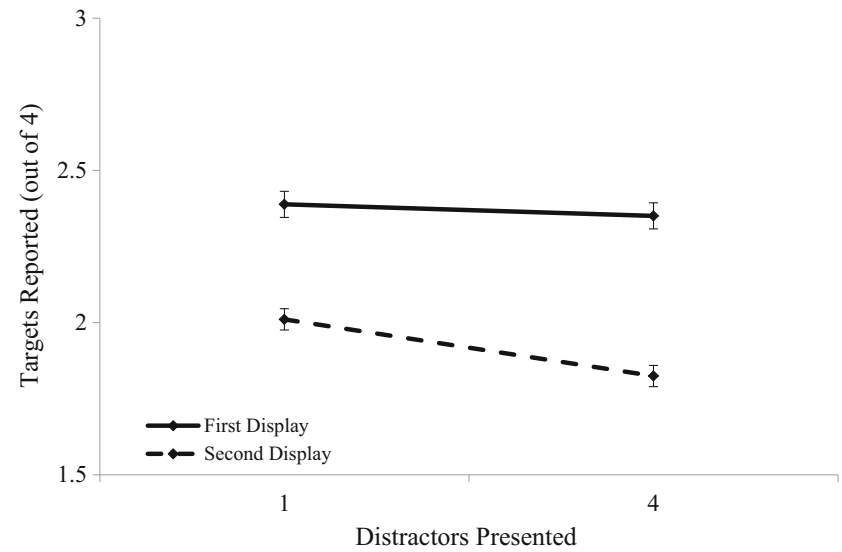

Fig. 4 Experiment 2: Mean numbers of targets reported in each display as a function of the number of distractors in that display. The solid line shows the number of first-display targets when 4 targets were presented in the first display, and the dashed line shows the number of second-display targets when 4 targets were presented in the second display. Error bars show Fisher's least significant difference for $p<.05$, calculated using the mean squared error and the degrees of freedom for the corresponding ANOVA interaction effect 


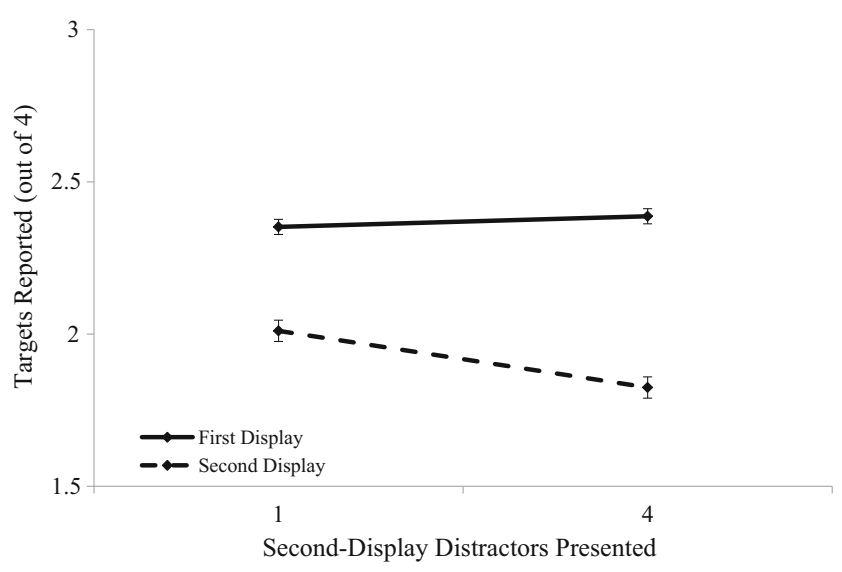

Fig. 5 Experiment 2: Mean numbers of targets reported from the first (solid line) and second (dashed line) displays as a function of the number of distractors presented in the second display. The results are shown for trials in which four targets were presented in each display. Error bars show Fisher's least significant difference for $p<.05$, calculated using the mean squared error and the degrees of freedom for the corresponding ANOVA interaction effect

second-display distractors on memory for the first-display targets. It could be that selection in perception and retention in STM involve different processes. It could also be that they are the same process but that we found no competition between perception and memory because the competition is modality-specific, such that only visuospatial representations in memory will compete with visuospatial representations in perception. If the visually presented targets were recoded into verbal labels in memory during the delay between displays, they may have been protected from the demands of the visually presented objects in the second display (because of the independence of the modalities; cf. Baddeley \& Hitch, 1974; Scarborough, 1972).

\section{Experiment 3: Two-display partial report with articulatory suppression}

In Experiment 3, the subjects were instructed to speak aloud during trials. Articulatory suppression should prevent verbal recoding and rehearsal (see Besner, 1987, for a review) and force the subjects to retain visuospatial representations of the first-display targets. These representations might suffer interference from the second-display distractors.

\section{Method}

Subjects We recruited 24 subjects in the Nashville area for Experiment 3. All were between the ages of 18 and 35, reported normal or corrected-to-normal vision, reported no color blindness, and had not participated in Experiment 1 or 2. The subjects were tested for $1.5 \mathrm{~h}$ and were compensated $\$ 18$ for their time.
Apparatus and stimuli At the beginning of each trial, subjects heard clicks to help them time their vocalizations. The sound file for these clicks was generated using a metronome in the GoldWave (version 5.70) software. All other aspects of the apparatus and stimuli were identical to those of Experiment 2.

Procedure The "Get Ready" screen at the beginning of each trial lasted $2.5 \mathrm{~s}$. While this screen was presented, subjects heard three clicks, occurring at a rate of three clicks per two seconds. A click occured $0.66 \mathrm{~s}, 1.33 \mathrm{~s}$, and $2 \mathrm{~s}$ after the onset of the screen. The "Get Ready" screen was extinguished $500 \mathrm{~ms}$ after the third click. Subjects were asked so say "Vanderbilt" out loud throughout each trial at a rate that matched the clicks, to start vocalizing immediately after the third click was heard, and to stop after the response was submitted for that trial. At the end of the experiment, subjects were asked to freely report any strategies they had used to help them remember the letters in the task. Additionally, they were asked whether they had tried to rehearse the letters and, if they did try, whether they thought the rehearsal helped. All other aspects of the procedure were identical to those of Experiment 2.

\section{Results and discussion}

We calculated the mean numbers of targets and distractors reported from each display. The full set of means is available in Table 5 in the appendices. We ran two 2 (first-display targets) $\times$ 2 (first-display distractors) $\times 2$ (second-display targets) $\times 2$ (second-display distractors) within-subjects ANOVAs to analyze the number of targets reported in each display. The output of these analyses is shown in Table 6 in the appendices. Onesided BFs are presented for the discussed effects.

We found competition among the targets in each display. Subjects reported both fewer first-display targets when more targets were presented in the second display, $F(1,23)=8.24, p$ $<.01, \mathrm{BF}=9.44(\mathrm{~A})$, and fewer second-display targets when more targets were presented in the first, $F(1,23)=41.68, p<$ $.001, \mathrm{BF}=29,961.97(\mathrm{~A})$.

Distractors reduced the number of targets reported from the display in which they were presented: $F(1,23)=9.30, p<.01$, $\mathrm{BF}=13.70(\mathrm{~A})$, for the first display, and $F(1,23)=55.19, p<$ $.001, \mathrm{BF}=243,110(\mathrm{~A})$, for the second. Figure 6 shows how the number of distractors presented in each display influenced target report from the display in which they were presented. The trends were very similar to those in Experiment 2.

As in Experiments 1 and 2, the number of distractors in the second display did not affect the number of targets reported from the first display, $F(1,23)=0.18, p>.05, \mathrm{BF}=8.71(\mathrm{~N})$. Figure 7 shows the effects of second-display distractors on first- and second-display target report. Second-display distractors reduced second-display, but not first-display, target report. 


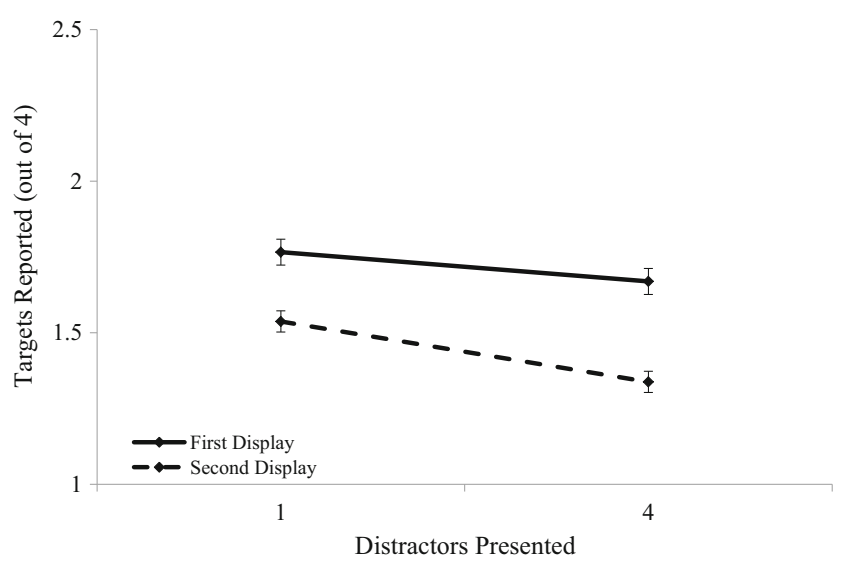

Fig. 6 Experiment 3: Mean numbers of targets reported in each display as a function of the number of distractors in that display. The solid line shows the numbers of first-display targets when 4 targets were presented in the first display, and the dashed line shows the numbers of seconddisplay targets when 4 targets were presented in the second display. Error bars show Fisher's least significant difference for $p<.05$, calculated using the mean squared error and the degrees of freedom for the corresponding ANOVA interaction effect

Ten of the 24 subjects $(41.67 \%)$ stated that they had tried to rehearse the letters in the task. Of those ten subjects, seven of them $(70 \%$ of those who reported rehearsal, $29.17 \%$ of all subjects) had abandoned the strategy because it was too difficult or did not seem to help. Thus, only three of the 24 participants $(12.5 \%)$ reported that they had successfully used rehearsal to remember the letters. Articulatory suppression thus successfully prevented rehearsal for most subjects. Removing the three subjects who rehearsed from the analyses did not change the results: Second-display distractors did not reduce firstdisplay target report, so objects in STM and objects in perception indeed may not compete for selective attention. However, our conclusions are tempered by the fact that, as in the first two

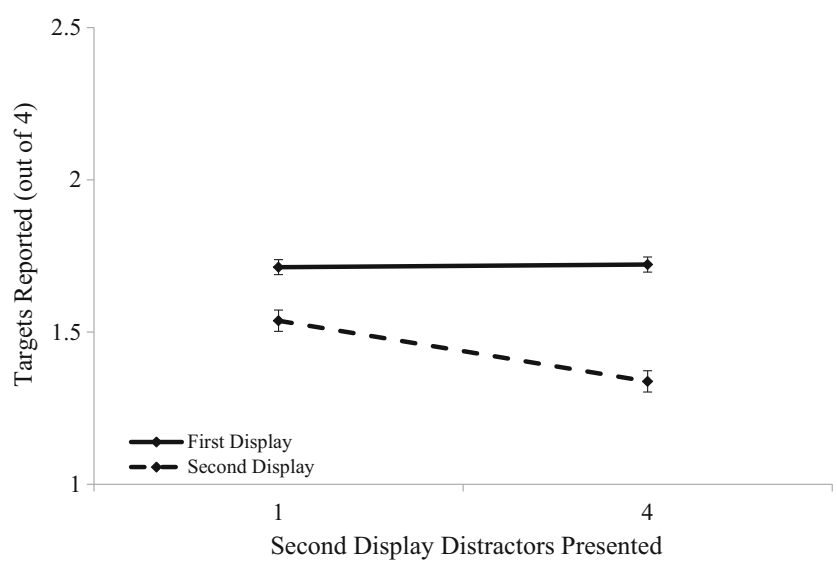

Fig. 7 Experiment 3: Mean numbers of targets reported from the first (solid line) and second displays (dashed line) as a function of the number of distractors presented in the second display. The results are shown for trials in which four targets were presented in each display. Error bars are Fisher's least significant difference for $p<.05$, calculated using the mean squared error and the degrees of freedom for the corresponding ANOVA interaction effect experiments, accuracy was higher in the first display than in the second, and the within-display effect of the first-display distractors was smaller than the within-display effect of the second-display distractors. Sustained attention may have been given to the objects in STM to keep them active, leaving less attention available to select targets in the second display. Alternatively, the objects in STM may still have been verbally recoded, despite the verbal reports suggesting otherwise. In Experiment 4, we attempted to prevent verbal recoding by using visuospatial stimuli rather than articulatory suppression.

\section{Experiment 4: Two-display partial report with rotated letters}

Letters are frequently rehearsed or implicitly named in the absence of an auditory load or articulatory suppression; when naming is prevented, memory performance decreases (but is not obliterated; cf. Scarborough, 1972). On the other hand, when the display duration is short, memory for object orientations is unaffected by the presence of an auditory load (Luck \& Vogel, 1997; Vogel et al., 2001), suggesting that the orientations are not verbally recoded. In Experiment 4, we attempted to remove verbal coding by having subjects report the orientations of presented letters. Subjects were shown two displays of rotated capital Ts. On each trial, subjects were cued with a target location, and they had to report the orientation of the $\mathrm{T}$ at that location.

\section{Method}

Subjects We recruited 24 subjects in the Nashville area for Experiment 4. All were between the ages of 18 and 35, reported normal or corrected-to-normal vision, reported no color blindness, and had not participated in Experiments 1-3. The subjects were tested for $1.5 \mathrm{~h}$ and were compensated $\$ 18$ for their time.

Apparatus and stimuli Only the letter $\mathrm{T}$ was presented in each display. The Ts were italicized and rotated to eight orientations: $0^{\circ}, 45^{\circ}, 90^{\circ}, 135^{\circ}, 180^{\circ}, 225^{\circ}, 270^{\circ}$, and $315^{\circ}$ (clockwise rotations). Because only eight orientations were available, duplicates in orientation were allowed. However, each combination of orientation and color could not repeat. The cells of the matrix presented in each display were visible to the subject. All other aspects of the apparatus and stimuli were identical to those of Experiment 2.

Procedure Subjects were explicitly told to keep their hands away from the keyboard until the response screen appeared, to prevent them from preparing their response. On the response screen, a $4 \times 4$ matrix was presented with one of its cells outlined in blue. The blue outline cued the subject to report the orientation of the $\mathrm{T}$ that had appeared at that location. The cue would only appear at locations where a target had been 
presented. On half of the trials a target location from the first display was cued, and on the other half a second-display location was cued. Figure 8 shows an example of the cue screen, as well as two displays that could have appeared in a trial.

Subjects gave their response using the number pad of the keyboard. The mapping of the keys matched the relative orientations of the Ts. For example, a $\mathrm{T}$ facing up and to the right was mapped to the "9" key, which is up and to the right of "5." No responses were mapped to the " 5 " key. Subjects made one response per trial. All other aspects of the procedure were identical to those of the second experiment.

\section{Results and discussion}

To make the results of Experiment 4 more comparable to those of the previous experiments, we calculated the number of objects in STM, $K$, using the following equation: $K=$ (proportion correct) $\times$ (number of targets presented in the display). Table 7 in the appendices shows the mean $K$ for each of the display compositions. We analyzed the effect of display composition on $K$ in each display by using a 2 (first-display targets) $\times 2$ (first-display distractors) $\times 2$ (second-display targets) $\times 2$ (second-display distractors) within-subjects ANOVA. The ANOVA effects are shown in Table 8 in the appendices. Onesided BFs are presented for the discussed effects.

Targets from the first display placed a limit on the number of second-display targets that could be represented in STM. $K$ for the second display decreased with the number of targets in the first display, $F(1,23)=7.43, p<.05, \mathrm{BF}=7.04(\mathrm{~A})$, but $K$ for the first display was not affected by the number of targets in the second display, $F(1,23)=0.02, p>.05, \mathrm{BF}=7.06(\mathrm{~N})$.

The distractors competed for selective attention within each display. The effects of distractors on $K$ within their respective displays are shown in Fig. 9. $K$ decreased in each display as the number or distractors within the respective display increased: $F(1,23)=9.54, p<.01, \mathrm{BF}=14.88(\mathrm{~A})$, for the first display, and $F(1,23)=4.43, p<.05, \mathrm{BF}=2.19(\mathrm{~A})$, for the second display.

Second-display distractors again did not compete with first-display targets: $K$ in the first display was unaffected by the number of distractors in the second display, $F(1,23)=$

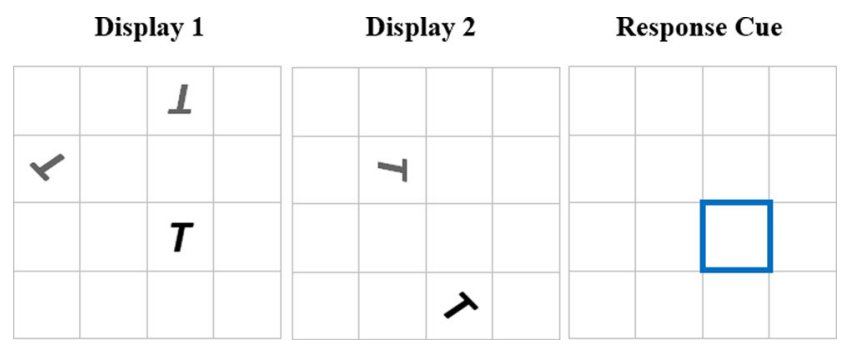

Fig. 8 Examples of two displays of letters that could have been presented in Experiment 4. In this example, the outlined cell indicates that the black upright $\mathrm{T}$ from Display 1 should be reported

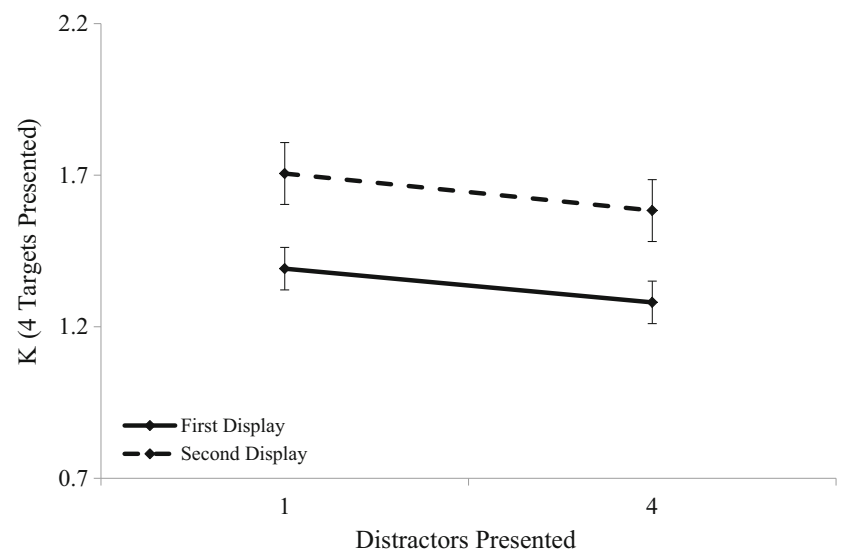

Fig. 9 Experiment 4: Mean $K$ for each display as a function of the number of distractors in that display. The solid line shows $K$ for the first display when 4 targets were presented in the first display, and the dashed line shows $K$ for the second display when 4 targets were presented in the second display. Error bars show Fisher's least significant difference for $p$ $<.05$, calculated using the mean squared error and the degrees of freedom for the corresponding ANOVA interaction effect

$3.00, p>.05, \mathrm{BF}=16.80(\mathrm{~N})$. Figure 10 shows this effect. The number of distractors in the second display reduced $K$ in the second display, but not in the first.

Having subjects report orientation prevented verbal recoding. None of the subjects in Experiment 4 reported rehearsing the orientations of the Ts. Additionally, accuracy was greater for the second display, and the within-display distractor effect was larger in the first display. Objects in memory and objects in perception thus do not compete for selective attention, and the lack of competition cannot be explained by verbal recoding or by attentional prioritization of first-display targets. The mechanism for selection in perception is not also used to retain items in STM.

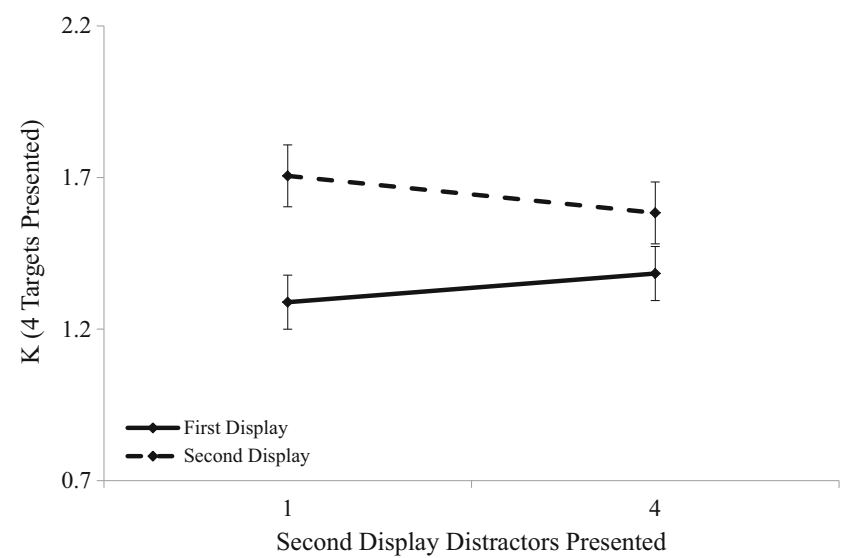

Fig. 10 Experiment 4: Mean $K$ s for the first (solid line) and second (dashed line) displays as a function of the number of distractors presented in the second display. The results are shown for trials in which four targets were presented in each display. Error bars show Fisher's least significant difference for $p<.05$, calculated using the mean squared error and the degrees of freedom for the corresponding ANOVA interaction effect 
Precision analysis Experiments 1-3 had required subjects to remember letter identities. Due to the categorical nature of letter identities, our analyses were limited to discrete counts; we could only assess how many target letters were reported. In Experiment 4, the subjects were asked to report a more continuous property of the letter stimuli. Although it is not perfectly continuous - we only presented eight different orientations - the metric nature of orientation allowed us to analyze the precision of the targets held in memory.

As the number of objects the subject needs to remember increases, the precision of each stored object decreases (Bays, Catalao, \& Husain, 2009; Zhang \& Luck, 2008). If the process that retains these objects in STM is the same as the one that selects new objects into STM, then distractors should reduce the precision of targets held in STM. In Fig. 11, we plot the proportions of trials on which a particular letter orientation was reported, centered on the correct orientation. If distractors reduce precision, then presenting more distractors should decrease report of the correct target orientation and increase report of disparate orientations. Neither result was obtained. Thus, the continuous analysis is consistent with our prior categorical analyses: Increasing the number of distractors in the second display did not reduce the precision of the targets held in STM.

\section{General discussion}

We conducted four experiments investigating the effect of perceptual distraction on retaining old objects within STM. In Experiment 1, we found that the number of letter identities retained from a display was not affected by the number of distracting letters presented in a subsequent display. In Experiment 2, we found that making the target and distractor letters more similar - in essence, making the distractors more

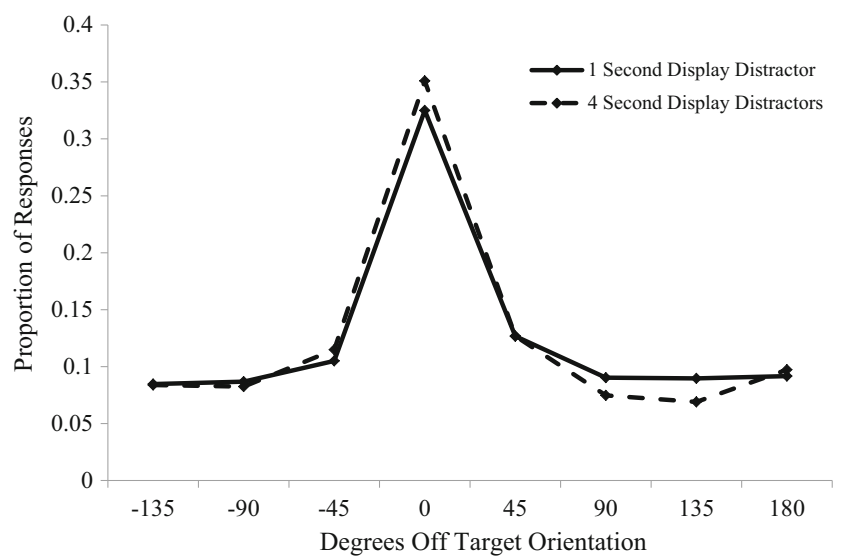

Fig. 11 Experiment 4: Proportions of responses for the eight possible orientations for trials in which the probed item was a first-display target. Orientation is centered (i.e., set to zero) on the orientation of the probed target object. Other orientations are given relative to the target orientation. Positive values indicate that the reported orientation was rotated clockwise relative to the target orientation, and negative values indicate counterclockwise rotation difficult to filter - did not reduce the number of objects retained in STM. In Experiments 3 and 4, we demonstrated that the objects in memory were unaffected by perceptual distraction, even when rehearsal was prevented. Making attentional selection difficult does not make the retention of prior information difficult.

\section{Attentional dwell time}

In this study, we focused on how perceiving new information affects the retention of old information. Research on attentional dwell time investigates this same interaction, in the opposite direction; it focuses on how retaining one target item affects the perception of a new target item. In this procedure, two masked target objects are presented, one after the other, and the time delay between the target presentations is manipulated. Subjects often find it difficult to perceive the second target when the delay between it and the previous target is short (generally between 200 and 500 ms; Duncan, Ward, \& Shapiro, 1994; but see Petersen, Kyllingsbæk, \& Bundesen, 2012; Theeuwes, Godijn, \& Pratt, 2004). Selective attention is locked onto the first target for a period of time after that target is presented; targets presented before selective attention is released are less likely to be processed (Petersen et al., 2012).

In our experiments, the delay between stimulus presentations was 1,000 ms. By this time, selective attention should have been released from the letters in the first display. We hypothesized that, when STM was full, selective attention would be redeployed to the letters in STM to prevent their loss, and that increasing the attention demand of the subsequent display would leave less attention available to STM. Our results suggest that selective attention is not redeployed to STM; once selective attention is released, the objects in STM are free from selective-attention demands. An effect of perceptual distraction on the objects in STM might be obtained if the distraction were presented during the attentional dwell time. To our knowledge, no research has investigated this effect.

\section{Search}

Work in the search literature has investigated whether maintenance in STM and visual search use a common process. The benchmark for making this comparison has been the slope of the function relating the number of items presented in a display (the array size) to the response time (Logan, 1978). If STM maintenance and visual search use the same process, the effect of memory load on response time should interact with the effect of array size - that is, memory load should increase the slope of the search function. Memory load interacts with array size when the memoranda are visuospatial in nature (Woodman \& Luck, 2004), but otherwise does not (Logan, 1976, 1978; Woodman, Vogel, \& Luck, 2001). 
More related to the present study is the effect of array size on the report of objects from memory. If STM and visual search use the same process, then a harder search (a larger array size) should reduce the number of objects reported from STM. Like the previously discussed interaction, array size only affects the number objects reported when the objects are visuospatial in nature (Logan, 1976, 1978; Woodman \& Luck, 2004; Woodman et al., 2001). Given this result, it is surprising that in Experiment 4, in which subjects also had to process a visual display with a visuospatial memory load, the number of distractors in the second display had no effect on the objects held in STM. The processes used to select and retain spatial information may not overlap as much as has previously been believed.

\section{A common resource?}

Past research has claimed that a common attention resource is used to select objects from perception and retain objects in STM (e.g., Kiyonaga \& Egner, 2014a, 2014b). We found conflicting evidence for this hypothesis. If a shared resource is used, one would expect that making selection difficult would create a greater demand for the resource, leaving less of it available to retain the targets in STM. This was not the case in our experiments; second-display distractors did not affect first-display target report. On the other hand, one would also expect that making retention difficult would make selection difficult. We did find this to be the case in Experiments 1 and 4 ; in these experiments, having to retain more first-display targets increased the effect of the distractors in the second display. Further investigation into this hypothesis is warranted.

\section{Conclusion}

We asked whether retention in STM and attentional selection in perception share the same mechanism. We addressed this question by analyzing how perceptual distraction affected the retention of objects in STM. Increasing the number of distracting objects makes choosing new objects difficult, but it does not affect old objects that are already chosen into STM. This lack of effect cannot be explained by the distractors being too easily filtered or by the objects in memory being verbally recoded. We conclude that selective attention chooses the objects in perception to bring into STM, but it does not choose which objects stay in memory. Other processes, possibly other types of attention (e.g., sustained, internally directed attention; Chun, 2011) or other forms of selection (e.g., late selection of categorical features; Cowan, 1988), determine which objects stay in memory.

Author note This work was supported by National Science Foundation Grant No. BCS 1257272.

\section{Appendix A: Experiment 1 descriptive statistics and ANOVA output tables}

Table 1 Descriptive statistics for each trial type in Experiment 1

\begin{tabular}{|c|c|c|c|c|c|c|c|c|c|c|c|c|}
\hline \multicolumn{2}{|c|}{$\begin{array}{l}\text { Display } 1 \\
\text { Presentation }\end{array}$} & \multicolumn{2}{|c|}{$\begin{array}{l}\text { Display } 2 \\
\text { Presentation }\end{array}$} & \multicolumn{4}{|c|}{ Display 1 Report } & \multicolumn{4}{|c|}{ Display 2 Report } & \multirow[b]{2}{*}{$N$} \\
\hline Targets & Distractors & Targets & Distractors & $\begin{array}{l}\text { Mean } \\
\text { Targets }\end{array}$ & $\begin{array}{l}S D \\
\text { Targets }\end{array}$ & $\begin{array}{l}\text { Mean } \\
\text { Distractors }\end{array}$ & $\begin{array}{l}S D \\
\text { Distractors }\end{array}$ & $\begin{array}{l}\text { Mean } \\
\text { Targets }\end{array}$ & $\begin{array}{l}S D \\
\text { Targets }\end{array}$ & $\begin{array}{l}\text { Mean } \\
\text { Distractors }\end{array}$ & $\begin{array}{l}S D \\
\text { Distractors }\end{array}$ & \\
\hline 0 & 1 & 0 & 1 & 0 & 0 & 0.04 & 0.14 & 0 & 0 & 0.02 & 0.10 & 24 \\
\hline 0 & 1 & 0 & 2 & 0 & 0 & 0.00 & 0.00 & 0 & 0 & 0.10 & 0.21 & 24 \\
\hline 0 & 1 & 0 & 3 & 0 & 0 & 0.06 & 0.17 & 0 & 0 & 0.15 & 0.43 & 24 \\
\hline 0 & 1 & 1 & 1 & 0 & 0 & 0.04 & 0.14 & 0.96 & 0.2 & 0.06 & 0.22 & 24 \\
\hline 0 & 1 & 1 & 2 & 0 & 0 & 0.04 & 0.14 & 0.98 & 0.1 & 0.06 & 0.17 & 24 \\
\hline 0 & 1 & 1 & 3 & 0 & 0 & 0.02 & 0.10 & 0.98 & 0.1 & 0.00 & 0.00 & 24 \\
\hline 0 & 1 & 2 & 1 & 0 & 0 & 0.00 & 0.00 & 1.73 & 0.36 & 0.00 & 0.00 & 24 \\
\hline 0 & 1 & 2 & 2 & 0 & 0 & 0.02 & 0.10 & 1.9 & 0.25 & 0.00 & 0.00 & 24 \\
\hline 0 & 1 & 2 & 3 & 0 & 0 & 0.02 & 0.10 & 1.83 & 0.28 & 0.13 & 0.27 & 24 \\
\hline 0 & 1 & 3 & 1 & 0 & 0 & 0.02 & 0.10 & 2.48 & 0.45 & 0.04 & 0.14 & 24 \\
\hline 0 & 1 & 3 & 2 & 0 & 0 & 0.08 & 0.24 & 2.44 & 0.71 & 0.17 & 0.28 & 24 \\
\hline 0 & 1 & 3 & 3 & 0 & 0 & 0.02 & 0.10 & 2.33 & 0.56 & 0.19 & 0.29 & 24 \\
\hline 0 & 1 & 4 & 1 & 0 & 0 & 0.02 & 0.10 & 3.04 & 0.62 & 0.08 & 0.19 & 24 \\
\hline 0 & 1 & 4 & 2 & 0 & 0 & 0.06 & 0.17 & 2.92 & 0.65 & 0.10 & 0.25 & 24 \\
\hline 0 & 1 & 4 & 3 & 0 & 0 & 0.08 & 0.19 & 2.65 & 0.88 & 0.19 & 0.29 & 22 \\
\hline
\end{tabular}


Table 1 (continued)

\begin{tabular}{|c|c|c|c|c|c|c|c|c|c|c|c|c|}
\hline \multicolumn{2}{|c|}{$\begin{array}{l}\text { Display } 1 \\
\text { Presentation }\end{array}$} & \multicolumn{2}{|c|}{$\begin{array}{l}\text { Display } 2 \\
\text { Presentation }\end{array}$} & \multicolumn{4}{|c|}{ Display 1 Report } & \multicolumn{4}{|c|}{ Display 2 Report } & \multirow[b]{2}{*}{$N$} \\
\hline Targets & Distractors & Targets & Distractors & $\begin{array}{l}\text { Mean } \\
\text { Targets }\end{array}$ & $\begin{array}{l}S D \\
\text { Targets }\end{array}$ & $\begin{array}{l}\text { Mean } \\
\text { Distractors }\end{array}$ & $\begin{array}{l}S D \\
\text { Distractors }\end{array}$ & $\begin{array}{l}\text { Mean } \\
\text { Targets }\end{array}$ & $\begin{array}{l}S D \\
\text { Targets }\end{array}$ & $\begin{array}{l}\text { Mean } \\
\text { Distractors }\end{array}$ & $\begin{array}{l}S D \\
\text { Distractors }\end{array}$ & \\
\hline 0 & 2 & 0 & 1 & 0 & 0 & 0.06 & 0.17 & 0 & 0 & 0.04 & 0.14 & 24 \\
\hline 0 & 2 & 0 & 2 & 0 & 0 & 0.08 & 0.24 & 0 & 0 & 0.10 & 0.25 & 24 \\
\hline 0 & 2 & 0 & 3 & 0 & 0 & 0.08 & 0.24 & 0 & 0 & 0.13 & 0.34 & 24 \\
\hline 0 & 2 & 1 & 1 & 0 & 0 & 0.06 & 0.22 & 0.96 & 0.14 & 0.04 & 0.14 & 24 \\
\hline 0 & 2 & 1 & 2 & 0 & 0 & 0.06 & 0.17 & 0.96 & 0.14 & 0.06 & 0.22 & 24 \\
\hline 0 & 2 & 1 & 3 & 0 & 0 & 0.06 & 0.22 & 0.92 & 0.19 & 0.15 & 0.28 & 24 \\
\hline 0 & 2 & 2 & 1 & 0 & 0 & 0.13 & 0.34 & 1.77 & 0.44 & 0.02 & 0.10 & 24 \\
\hline 0 & 2 & 2 & 2 & 0 & 0 & 0.10 & 0.25 & 1.81 & 0.29 & 0.04 & 0.14 & 24 \\
\hline 0 & 2 & 2 & 3 & 0 & 0 & 0.17 & 0.28 & 1.79 & 0.39 & 0.21 & 0.33 & 24 \\
\hline 0 & 2 & 3 & 1 & 0 & 0 & 0.08 & 0.24 & 2.6 & 0.47 & 0.06 & 0.22 & 24 \\
\hline 0 & 2 & 3 & 2 & 0 & 0 & 0.19 & 0.25 & 2.48 & 0.56 & 0.15 & 0.31 & 24 \\
\hline 0 & 2 & 3 & 3 & 0 & 0 & 0.06 & 0.22 & 2.6 & 0.47 & 0.19 & 0.29 & 24 \\
\hline 0 & 2 & 4 & 1 & 0 & 0 & 0.13 & 0.27 & 2.75 & 0.69 & 0.04 & 0.14 & 24 \\
\hline 0 & 2 & 4 & 2 & 0 & 0 & 0.15 & 0.28 & 2.79 & 0.69 & 0.17 & 0.32 & 24 \\
\hline 0 & 2 & 4 & 3 & 0 & 0 & 0.10 & 0.21 & 2.9 & 0.75 & 0.23 & 0.33 & 24 \\
\hline 0 & 3 & 0 & 1 & 0 & 0 & 0.19 & 0.36 & 0 & 0 & 0.00 & 0.00 & 24 \\
\hline 0 & 3 & 0 & 2 & 0 & 0 & 0.17 & 0.28 & 0 & 0 & 0.06 & 0.17 & 24 \\
\hline 0 & 3 & 0 & 3 & 0 & 0 & 0.15 & 0.28 & 0 & 0 & 0.17 & 0.35 & 24 \\
\hline 0 & 3 & 1 & 1 & 0 & 0 & 0.19 & 0.38 & 0.96 & 0.14 & 0.02 & 0.10 & 24 \\
\hline 0 & 3 & 1 & 2 & 0 & 0 & 0.17 & 0.50 & 0.96 & 0.14 & 0.06 & 0.17 & 24 \\
\hline 0 & 3 & 1 & 3 & 0 & 0 & 0.08 & 0.32 & 0.96 & 0.14 & 0.19 & 0.25 & 24 \\
\hline 0 & 3 & 2 & 1 & 0 & 0 & 0.10 & 0.21 & 1.83 & 0.28 & 0.02 & 0.10 & 24 \\
\hline 0 & 3 & 2 & 2 & 0 & 0 & 0.04 & 0.14 & 1.88 & 0.22 & 0.06 & 0.17 & 24 \\
\hline 0 & 3 & 2 & 3 & 0 & 0 & 0.15 & 0.35 & 1.83 & 0.24 & 0.08 & 0.19 & 24 \\
\hline 0 & 3 & 3 & 1 & 0 & 0 & 0.13 & 0.27 & 2.48 & 0.45 & 0.10 & 0.21 & 24 \\
\hline 0 & 3 & 3 & 2 & 0 & 0 & 0.21 & 0.39 & 2.35 & 0.56 & 0.08 & 0.19 & 24 \\
\hline 0 & 3 & 3 & 3 & 0 & 0 & 0.25 & 0.39 & 2.56 & 0.43 & 0.15 & 0.23 & 24 \\
\hline 0 & 3 & 4 & 1 & 0 & 0 & 0.29 & 0.44 & 3.04 & 0.46 & 0.02 & 0.10 & 24 \\
\hline 0 & 3 & 4 & 2 & 0 & 0 & 0.29 & 0.33 & 2.9 & 0.69 & 0.04 & 0.14 & 24 \\
\hline 0 & 3 & 4 & 3 & 0 & 0 & 0.21 & 0.33 & 2.58 & 0.56 & 0.23 & 0.39 & 24 \\
\hline 1 & 1 & 0 & 1 & 0.94 & 0.17 & 0.02 & 0.10 & 0 & 0 & 0.06 & 0.17 & 24 \\
\hline 1 & 1 & 0 & 2 & 0.98 & 0.1 & 0.00 & 0.00 & 0 & 0 & 0.13 & 0.27 & 24 \\
\hline 1 & 1 & 0 & 3 & 0.92 & 0.19 & 0.00 & 0.00 & 0 & 0 & 0.15 & 0.43 & 24 \\
\hline 1 & 1 & 1 & 1 & 1 & 0 & 0.04 & 0.14 & 0.94 & 0.17 & 0.04 & 0.14 & 24 \\
\hline 1 & 1 & 1 & 2 & 0.98 & 0.1 & 0.02 & 0.10 & 0.85 & 0.28 & 0.06 & 0.17 & 24 \\
\hline 1 & 1 & 1 & 3 & 0.94 & 0.22 & 0.04 & 0.14 & 0.96 & 0.14 & 0.19 & 0.36 & 24 \\
\hline 1 & 1 & 2 & 1 & 0.96 & 0.14 & 0.02 & 0.10 & 1.77 & 0.33 & 0.02 & 0.10 & 24 \\
\hline 1 & 1 & 2 & 2 & 0.94 & 0.22 & 0.02 & 0.10 & 1.77 & 0.39 & 0.06 & 0.17 & 24 \\
\hline 1 & 1 & 2 & 3 & 0.98 & 0.1 & 0.00 & 0.00 & 1.88 & 0.22 & 0.04 & 0.14 & 24 \\
\hline 1 & 1 & 3 & 1 & 0.92 & 0.19 & 0.02 & 0.10 & 2.4 & 0.59 & 0.06 & 0.17 & 24 \\
\hline 1 & 1 & 3 & 2 & 0.94 & 0.22 & 0.02 & 0.10 & 2.21 & 0.66 & 0.19 & 0.32 & 24 \\
\hline 1 & 1 & 3 & 3 & 0.96 & 0.14 & 0.04 & 0.14 & 2.33 & 0.55 & 0.13 & 0.22 & 24 \\
\hline 1 & 1 & 4 & 1 & 0.92 & 0.19 & 0.02 & 0.10 & 2.63 & 0.76 & 0.08 & 0.24 & 24 \\
\hline 1 & 1 & 4 & 2 & 0.96 & 0.14 & 0.06 & 0.17 & 2.54 & 0.55 & 0.17 & 0.28 & 24 \\
\hline 1 & 1 & 4 & 3 & 0.88 & 0.22 & 0.06 & 0.17 & 2.52 & 0.68 & 0.17 & 0.28 & 24 \\
\hline 1 & 2 & 0 & 1 & 0.94 & 0.22 & 0.04 & 0.14 & 0 & 0 & 0.02 & 0.10 & 24 \\
\hline
\end{tabular}


Table 1 (continued)

\begin{tabular}{|c|c|c|c|c|c|c|c|c|c|c|c|c|}
\hline \multicolumn{2}{|c|}{$\begin{array}{l}\text { Display } 1 \\
\text { Presentation }\end{array}$} & \multicolumn{2}{|c|}{$\begin{array}{l}\text { Display } 2 \\
\text { Presentation }\end{array}$} & \multicolumn{4}{|c|}{ Display 1 Report } & \multicolumn{4}{|c|}{ Display 2 Report } & \multirow[b]{2}{*}{$N$} \\
\hline Targets & Distractors & Targets & Distractors & $\begin{array}{l}\text { Mean } \\
\text { Targets }\end{array}$ & $\begin{array}{l}S D \\
\text { Targets }\end{array}$ & $\begin{array}{l}\text { Mean } \\
\text { Distractors }\end{array}$ & $\begin{array}{l}S D \\
\text { Distractors }\end{array}$ & $\begin{array}{l}\text { Mean } \\
\text { Targets }\end{array}$ & $\begin{array}{l}S D \\
\text { Targets }\end{array}$ & $\begin{array}{l}\text { Mean } \\
\text { Distractors }\end{array}$ & $\begin{array}{l}S D \\
\text { Distractors }\end{array}$ & \\
\hline 1 & 2 & 0 & 2 & 0.98 & 0.1 & 0.08 & 0.19 & 0 & 0 & 0.04 & 0.14 & 24 \\
\hline 1 & 2 & 0 & 3 & 0.96 & 0.14 & 0.10 & 0.21 & 0 & 0 & 0.15 & 0.31 & 24 \\
\hline 1 & 2 & 1 & 1 & 0.98 & 0.1 & 0.04 & 0.14 & 0.94 & 0.17 & 0.02 & 0.10 & 24 \\
\hline 1 & 2 & 1 & 2 & 0.9 & 0.21 & 0.02 & 0.10 & 0.94 & 0.17 & 0.00 & 0.00 & 24 \\
\hline 1 & 2 & 1 & 3 & 0.98 & 0.1 & 0.08 & 0.28 & 0.94 & 0.22 & 0.04 & 0.14 & 24 \\
\hline 1 & 2 & 2 & 1 & 0.88 & 0.22 & 0.10 & 0.25 & 1.71 & 0.33 & 0.02 & 0.10 & 24 \\
\hline 1 & 2 & 2 & 2 & 0.98 & 0.1 & 0.10 & 0.21 & 1.79 & 0.36 & 0.06 & 0.17 & 24 \\
\hline 1 & 2 & 2 & 3 & 0.92 & 0.19 & 0.04 & 0.14 & 1.81 & 0.32 & 0.15 & 0.28 & 24 \\
\hline 1 & 2 & 3 & 1 & 0.92 & 0.19 & 0.04 & 0.14 & 2.42 & 0.72 & 0.00 & 0.00 & 24 \\
\hline 1 & 2 & 3 & 2 & 0.96 & 0.14 & 0.19 & 0.29 & 2.38 & 0.77 & 0.04 & 0.14 & 24 \\
\hline 1 & 2 & 3 & 3 & 0.9 & 0.21 & 0.15 & 0.23 & 2.4 & 0.64 & 0.15 & 0.28 & 24 \\
\hline 1 & 2 & 4 & 1 & 0.85 & 0.28 & 0.15 & 0.31 & 2.35 & 0.68 & 0.13 & 0.27 & 24 \\
\hline 1 & 2 & 4 & 2 & 0.96 & 0.14 & 0.08 & 0.19 & 2.4 & 0.92 & 0.08 & 0.19 & 24 \\
\hline 1 & 2 & 4 & 3 & 0.96 & 0.14 & 0.10 & 0.25 & 2.42 & 0.78 & 0.31 & 0.41 & 24 \\
\hline 1 & 3 & 0 & 1 & 0.98 & 0.1 & 0.13 & 0.27 & 0 & 0 & 0.02 & 0.10 & 24 \\
\hline 1 & 3 & 0 & 2 & 0.98 & 0.1 & 0.17 & 0.28 & 0 & 0 & 0.04 & 0.14 & 24 \\
\hline 1 & 3 & 0 & 3 & 0.96 & 0.14 & 0.10 & 0.25 & 0 & 0 & 0.15 & 0.38 & 24 \\
\hline 1 & 3 & 1 & 1 & 0.9 & 0.21 & 0.13 & 0.27 & 0.9 & 0.25 & 0.00 & 0.00 & 24 \\
\hline 1 & 3 & 1 & 2 & 0.9 & 0.21 & 0.08 & 0.19 & 0.88 & 0.22 & 0.00 & 0.00 & 24 \\
\hline 1 & 3 & 1 & 3 & 0.98 & 0.1 & 0.15 & 0.28 & 1 & 0 & 0.13 & 0.27 & 24 \\
\hline 1 & 3 & 2 & 1 & 0.96 & 0.14 & 0.19 & 0.29 & 1.73 & 0.42 & 0.06 & 0.17 & 24 \\
\hline 1 & 3 & 2 & 2 & 0.96 & 0.14 & 0.13 & 0.27 & 1.88 & 0.27 & 0.02 & 0.10 & 24 \\
\hline 1 & 3 & 2 & 3 & 0.94 & 0.17 & 0.25 & 0.42 & 1.79 & 0.39 & 0.23 & 0.39 & 24 \\
\hline 1 & 3 & 3 & 1 & 0.9 & 0.21 & 0.27 & 0.49 & 2.29 & 0.57 & 0.06 & 0.17 & 24 \\
\hline 1 & 3 & 3 & 2 & 0.98 & 0.1 & 0.13 & 0.27 & 2.48 & 0.48 & 0.04 & 0.14 & 24 \\
\hline 1 & 3 & 3 & 3 & 0.94 & 0.17 & 0.10 & 0.21 & 2.31 & 0.51 & 0.19 & 0.32 & 24 \\
\hline 1 & 3 & 4 & 1 & 0.92 & 0.19 & 0.23 & 0.33 & 2.54 & 0.81 & 0.02 & 0.10 & 24 \\
\hline 1 & 3 & 4 & 2 & 0.9 & 0.25 & 0.35 & 0.45 & 2.52 & 0.77 & 0.13 & 0.27 & 24 \\
\hline 1 & 3 & 4 & 3 & 0.88 & 0.27 & 0.21 & 0.29 & 2.27 & 0.75 & 0.23 & 0.33 & 24 \\
\hline 2 & 1 & 0 & 1 & 1.96 & 0.2 & 0.02 & 0.10 & 0 & 0 & 0.04 & 0.14 & 24 \\
\hline 2 & 1 & 0 & 2 & 1.88 & 0.22 & 0.00 & 0.00 & 0 & 0 & 0.10 & 0.33 & 24 \\
\hline 2 & 1 & 0 & 3 & 1.9 & 0.25 & 0.00 & 0.00 & 0 & 0 & 0.15 & 0.23 & 24 \\
\hline 2 & 1 & 1 & 1 & 1.92 & 0.24 & 0.02 & 0.10 & 0.9 & 0.25 & 0.04 & 0.14 & 24 \\
\hline 2 & 1 & 1 & 2 & 1.9 & 0.25 & 0.00 & 0.00 & 0.94 & 0.17 & 0.06 & 0.22 & 24 \\
\hline 2 & 1 & 1 & 3 & 1.88 & 0.3 & 0.06 & 0.17 & 0.83 & 0.32 & 0.06 & 0.22 & 24 \\
\hline 2 & 1 & 2 & 1 & 1.73 & 0.42 & 0.06 & 0.17 & 1.75 & 0.47 & 0.02 & 0.10 & 24 \\
\hline 2 & 1 & 2 & 2 & 1.88 & 0.22 & 0.00 & 0.00 & 1.73 & 0.42 & 0.02 & 0.10 & 24 \\
\hline 2 & 1 & 2 & 3 & 1.81 & 0.32 & 0.06 & 0.17 & 1.75 & 0.36 & 0.08 & 0.19 & 24 \\
\hline 2 & 1 & 3 & 1 & 1.79 & 0.39 & 0.02 & 0.10 & 2.08 & 0.8 & 0.04 & 0.14 & 24 \\
\hline 2 & 1 & 3 & 2 & 1.9 & 0.25 & 0.04 & 0.14 & 2.04 & 0.64 & 0.10 & 0.21 & 24 \\
\hline 2 & 1 & 3 & 3 & 1.71 & 0.33 & 0.08 & 0.19 & 2.17 & 0.64 & 0.15 & 0.35 & 24 \\
\hline 2 & 1 & 4 & 1 & 1.85 & 0.23 & 0.04 & 0.14 & 2.25 & 0.72 & 0.08 & 0.19 & 24 \\
\hline 2 & 1 & 4 & 2 & 1.85 & 0.28 & 0.06 & 0.17 & 2.23 & 0.91 & 0.06 & 0.17 & 24 \\
\hline 2 & 1 & 4 & 3 & 1.79 & 0.41 & 0.00 & 0.00 & 2.44 & 0.68 & 0.15 & 0.31 & 24 \\
\hline 2 & 2 & 0 & 1 & 1.79 & 0.33 & 0.06 & 0.17 & 0 & 0 & 0.00 & 0.00 & 24 \\
\hline 2 & 2 & 0 & 2 & 1.9 & 0.25 & 0.08 & 0.24 & 0 & 0 & 0.10 & 0.25 & 24 \\
\hline
\end{tabular}


Table 1 (continued)

\begin{tabular}{|c|c|c|c|c|c|c|c|c|c|c|c|c|}
\hline \multicolumn{2}{|c|}{$\begin{array}{l}\text { Display } 1 \\
\text { Presentation }\end{array}$} & \multicolumn{2}{|c|}{$\begin{array}{l}\text { Display } 2 \\
\text { Presentation }\end{array}$} & \multicolumn{4}{|c|}{ Display 1 Report } & \multicolumn{4}{|c|}{ Display 2 Report } & \multirow[b]{2}{*}{$N$} \\
\hline Targets & Distractors & Targets & Distractors & $\begin{array}{l}\text { Mean } \\
\text { Targets }\end{array}$ & $\begin{array}{l}S D \\
\text { Targets }\end{array}$ & $\begin{array}{l}\text { Mean } \\
\text { Distractors }\end{array}$ & $\begin{array}{l}S D \\
\text { Distractors }\end{array}$ & $\begin{array}{l}\text { Mean } \\
\text { Targets }\end{array}$ & $\begin{array}{l}S D \\
\text { Targets }\end{array}$ & $\begin{array}{l}\text { Mean } \\
\text { Distractors }\end{array}$ & $\begin{array}{l}S D \\
\text { Distractors }\end{array}$ & \\
\hline 2 & 2 & 0 & 3 & 1.79 & 0.39 & 0.10 & 0.21 & 0 & 0 & 0.17 & 0.28 & 24 \\
\hline 2 & 2 & 1 & 1 & 1.79 & 0.39 & 0.08 & 0.24 & 0.96 & 0.14 & 0.02 & 0.10 & 24 \\
\hline 2 & 2 & 1 & 2 & 1.88 & 0.27 & 0.10 & 0.21 & 0.92 & 0.19 & 0.06 & 0.22 & 24 \\
\hline 2 & 2 & 1 & 3 & 1.85 & 0.31 & 0.02 & 0.10 & 0.92 & 0.19 & 0.13 & 0.27 & 24 \\
\hline 2 & 2 & 2 & 1 & 1.9 & 0.33 & 0.02 & 0.10 & 1.69 & 0.38 & 0.04 & 0.14 & 24 \\
\hline 2 & 2 & 2 & 2 & 1.85 & 0.23 & 0.02 & 0.10 & 1.69 & 0.44 & 0.19 & 0.38 & 24 \\
\hline 2 & 2 & 2 & 3 & 1.94 & 0.17 & 0.08 & 0.19 & 1.67 & 0.48 & 0.10 & 0.33 & 24 \\
\hline 2 & 2 & 3 & 1 & 1.79 & 0.41 & 0.15 & 0.28 & 2.31 & 0.6 & 0.08 & 0.19 & 24 \\
\hline 2 & 2 & 3 & 2 & 1.83 & 0.28 & 0.08 & 0.19 & 2.21 & 0.92 & 0.08 & 0.19 & 24 \\
\hline 2 & 2 & 3 & 3 & 1.79 & 0.29 & 0.13 & 0.27 & 2.23 & 0.61 & 0.15 & 0.28 & 24 \\
\hline 2 & 2 & 4 & 1 & 1.88 & 0.27 & 0.04 & 0.14 & 2.31 & 0.86 & 0.08 & 0.19 & 24 \\
\hline 2 & 2 & 4 & 2 & 1.83 & 0.38 & 0.08 & 0.19 & 2.42 & 0.73 & 0.06 & 0.17 & 24 \\
\hline 2 & 2 & 4 & 3 & 1.92 & 0.19 & 0.10 & 0.21 & 2.33 & 0.99 & 0.23 & 0.29 & 24 \\
\hline 2 & 3 & 0 & 1 & 1.83 & 0.32 & 0.17 & 0.35 & 0 & 0 & 0.02 & 0.10 & 24 \\
\hline 2 & 3 & 0 & 2 & 1.83 & 0.32 & 0.08 & 0.24 & 0 & 0 & 0.04 & 0.20 & 24 \\
\hline 2 & 3 & 0 & 3 & 1.96 & 0.14 & 0.04 & 0.14 & 0 & 0 & 0.21 & 0.33 & 24 \\
\hline 2 & 3 & 1 & 1 & 1.96 & 0.14 & 0.04 & 0.14 & 0.94 & 0.17 & 0.04 & 0.14 & 24 \\
\hline 2 & 3 & 1 & 2 & 1.81 & 0.46 & 0.08 & 0.24 & 0.94 & 0.17 & 0.06 & 0.17 & 24 \\
\hline 2 & 3 & 1 & 3 & 1.85 & 0.23 & 0.06 & 0.17 & 0.9 & 0.21 & 0.21 & 0.25 & 24 \\
\hline 2 & 3 & 2 & 1 & 1.75 & 0.49 & 0.10 & 0.21 & 1.85 & 0.28 & 0.06 & 0.17 & 24 \\
\hline 2 & 3 & 2 & 2 & 1.92 & 0.19 & 0.17 & 0.28 & 1.77 & 0.47 & 0.08 & 0.19 & 24 \\
\hline 2 & 3 & 2 & 3 & 1.92 & 0.24 & 0.17 & 0.28 & 1.73 & 0.44 & 0.08 & 0.19 & 24 \\
\hline 2 & 3 & 3 & 1 & 1.69 & 0.41 & 0.21 & 0.33 & 2.31 & 0.67 & 0.04 & 0.14 & 24 \\
\hline 2 & 3 & 3 & 2 & 1.83 & 0.32 & 0.10 & 0.21 & 2.33 & 0.52 & 0.17 & 0.28 & 24 \\
\hline 2 & 3 & 3 & 3 & 1.83 & 0.35 & 0.21 & 0.33 & 2.27 & 0.72 & 0.15 & 0.23 & 24 \\
\hline 2 & 3 & 4 & 1 & 1.65 & 0.52 & 0.33 & 0.48 & 2.35 & 0.74 & 0.13 & 0.27 & 24 \\
\hline 2 & 3 & 4 & 2 & 1.85 & 0.28 & 0.13 & 0.34 & 2.44 & 0.65 & 0.17 & 0.28 & 24 \\
\hline 2 & 3 & 4 & 3 & 1.71 & 0.49 & 0.21 & 0.33 & 2.38 & 0.88 & 0.27 & 0.36 & 24 \\
\hline 3 & 1 & 0 & 1 & 2.73 & 0.29 & 0.06 & 0.17 & 0 & 0 & 0.04 & 0.14 & 24 \\
\hline 3 & 1 & 0 & 2 & 2.65 & 0.48 & 0.00 & 0.00 & 0 & 0 & 0.10 & 0.25 & 24 \\
\hline 3 & 1 & 0 & 3 & 2.69 & 0.48 & 0.04 & 0.14 & 0 & 0 & 0.21 & 0.33 & 24 \\
\hline 3 & 1 & 1 & 1 & 2.69 & 0.36 & 0.08 & 0.19 & 0.88 & 0.3 & 0.06 & 0.17 & 24 \\
\hline 3 & 1 & 1 & 2 & 2.46 & 0.51 & 0.04 & 0.14 & 0.9 & 0.21 & 0.15 & 0.28 & 24 \\
\hline 3 & 1 & 1 & 3 & 2.54 & 0.57 & 0.06 & 0.17 & 0.83 & 0.24 & 0.15 & 0.35 & 24 \\
\hline 3 & 1 & 2 & 1 & 2.56 & 0.5 & 0.06 & 0.17 & 1.63 & 0.54 & 0.02 & 0.10 & 24 \\
\hline 3 & 1 & 2 & 2 & 2.63 & 0.4 & 0.04 & 0.14 & 1.63 & 0.42 & 0.13 & 0.22 & 24 \\
\hline 3 & 1 & 2 & 3 & 2.54 & 0.57 & 0.04 & 0.14 & 1.65 & 0.48 & 0.19 & 0.32 & 24 \\
\hline 3 & 1 & 3 & 1 & 2.48 & 0.7 & 0.15 & 0.23 & 2.19 & 0.67 & 0.04 & 0.14 & 24 \\
\hline 3 & 1 & 3 & 2 & 2.54 & 0.55 & 0.02 & 0.10 & 2 & 0.72 & 0.04 & 0.14 & 24 \\
\hline 3 & 1 & 3 & 3 & 2.56 & 0.47 & 0.06 & 0.17 & 1.98 & 0.81 & 0.13 & 0.22 & 24 \\
\hline 3 & 1 & 4 & 1 & 2.42 & 0.52 & 0.04 & 0.14 & 2.31 & 1 & 0.02 & 0.10 & 24 \\
\hline 3 & 1 & 4 & 2 & 2.63 & 0.49 & 0.02 & 0.10 & 2 & 0.88 & 0.10 & 0.21 & 24 \\
\hline 3 & 1 & 4 & 3 & 2.6 & 0.53 & 0.04 & 0.14 & 1.98 & 0.85 & 0.15 & 0.28 & 24 \\
\hline 3 & 2 & 0 & 1 & 2.71 & 0.33 & 0.08 & 0.19 & 0 & 0 & 0.06 & 0.22 & 24 \\
\hline 3 & 2 & 0 & 2 & 2.71 & 0.44 & 0.13 & 0.22 & 0 & 0 & 0.21 & 0.33 & 24 \\
\hline 3 & 2 & 0 & 3 & 2.54 & 0.49 & 0.06 & 0.17 & 0 & 0 & 0.25 & 0.39 & 24 \\
\hline
\end{tabular}


Table 1 (continued)

\begin{tabular}{|c|c|c|c|c|c|c|c|c|c|c|c|c|}
\hline \multicolumn{2}{|c|}{$\begin{array}{l}\text { Display } 1 \\
\text { Presentation }\end{array}$} & \multicolumn{2}{|c|}{$\begin{array}{l}\text { Display } 2 \\
\text { Presentation }\end{array}$} & \multicolumn{4}{|c|}{ Display 1 Report } & \multicolumn{4}{|c|}{ Display 2 Report } & \multirow[b]{2}{*}{$N$} \\
\hline Targets & Distractors & Targets & Distractors & $\begin{array}{l}\text { Mean } \\
\text { Targets }\end{array}$ & $\begin{array}{l}S D \\
\text { Targets }\end{array}$ & $\begin{array}{l}\text { Mean } \\
\text { Distractors }\end{array}$ & $\begin{array}{l}S D \\
\text { Distractors }\end{array}$ & $\begin{array}{l}\text { Mean } \\
\text { Targets }\end{array}$ & $\begin{array}{l}S D \\
\text { Targets }\end{array}$ & $\begin{array}{l}\text { Mean } \\
\text { Distractors }\end{array}$ & $\begin{array}{l}S D \\
\text { Distractors }\end{array}$ & \\
\hline 3 & 2 & 1 & 1 & 2.56 & 0.6 & 0.08 & 0.19 & 0.81 & 0.25 & 0.08 & 0.19 & 24 \\
\hline 3 & 2 & 1 & 2 & 2.69 & 0.59 & 0.06 & 0.17 & 0.92 & 0.19 & 0.13 & 0.27 & 24 \\
\hline 3 & 2 & 1 & 3 & 2.63 & 0.49 & 0.00 & 0.00 & 0.92 & 0.19 & 0.10 & 0.21 & 24 \\
\hline 3 & 2 & 2 & 1 & 2.75 & 0.39 & 0.08 & 0.19 & 1.67 & 0.43 & 0.10 & 0.21 & 24 \\
\hline 3 & 2 & 2 & 2 & 2.52 & 0.63 & 0.06 & 0.17 & 1.6 & 0.44 & 0.08 & 0.19 & 24 \\
\hline 3 & 2 & 2 & 3 & 2.52 & 0.5 & 0.08 & 0.19 & 1.58 & 0.55 & 0.15 & 0.28 & 24 \\
\hline 3 & 2 & 3 & 1 & 2.58 & 0.52 & 0.08 & 0.24 & 2.08 & 0.89 & 0.02 & 0.10 & 24 \\
\hline 3 & 2 & 3 & 2 & 2.56 & 0.76 & 0.06 & 0.17 & 1.96 & 0.87 & 0.19 & 0.36 & 24 \\
\hline 3 & 2 & 3 & 3 & 2.6 & 0.63 & 0.17 & 0.24 & 1.77 & 0.75 & 0.15 & 0.31 & 24 \\
\hline 3 & 2 & 4 & 1 & 2.54 & 0.44 & 0.17 & 0.28 & 2.13 & 0.8 & 0.08 & 0.19 & 24 \\
\hline 3 & 2 & 4 & 2 & 2.35 & 0.58 & 0.21 & 0.29 & 2.02 & 1.03 & 0.15 & 0.28 & 24 \\
\hline 3 & 2 & 4 & 3 & 2.54 & 0.46 & 0.10 & 0.21 & 1.96 & 0.81 & 0.17 & 0.24 & 24 \\
\hline 3 & 3 & 0 & 1 & 2.6 & 0.53 & 0.08 & 0.24 & 0 & 0 & 0.08 & 0.19 & 24 \\
\hline 3 & 3 & 0 & 2 & 2.52 & 0.58 & 0.17 & 0.28 & 0 & 0 & 0.23 & 0.33 & 24 \\
\hline 3 & 3 & 0 & 3 & 2.73 & 0.39 & 0.13 & 0.27 & 0 & 0 & 0.19 & 0.29 & 24 \\
\hline 3 & 3 & 1 & 1 & 2.67 & 0.43 & 0.17 & 0.35 & 0.94 & 0.17 & 0.02 & 0.10 & 24 \\
\hline 3 & 3 & 1 & 2 & 2.48 & 0.5 & 0.17 & 0.24 & 0.88 & 0.27 & 0.10 & 0.25 & 24 \\
\hline 3 & 3 & 1 & 3 & 2.71 & 0.36 & 0.06 & 0.17 & 0.9 & 0.21 & 0.15 & 0.23 & 24 \\
\hline 3 & 3 & 2 & 1 & 2.5 & 0.63 & 0.10 & 0.21 & 1.69 & 0.48 & 0.06 & 0.17 & 24 \\
\hline 3 & 3 & 2 & 2 & 2.52 & 0.58 & 0.21 & 0.29 & 1.58 & 0.58 & 0.06 & 0.17 & 24 \\
\hline 3 & 3 & 2 & 3 & 2.52 & 0.65 & 0.15 & 0.28 & 1.65 & 0.45 & 0.15 & 0.31 & 24 \\
\hline 3 & 3 & 3 & 1 & 2.67 & 0.52 & 0.17 & 0.24 & 2.19 & 0.78 & 0.06 & 0.17 & 24 \\
\hline 3 & 3 & 3 & 2 & 2.35 & 0.48 & 0.23 & 0.29 & 2.23 & 0.66 & 0.13 & 0.22 & 24 \\
\hline 3 & 3 & 3 & 3 & 2.54 & 0.51 & 0.17 & 0.24 & 1.96 & 0.69 & 0.19 & 0.36 & 24 \\
\hline 3 & 3 & 4 & 1 & 2.46 & 0.55 & 0.23 & 0.29 & 2.38 & 0.66 & 0.04 & 0.14 & 24 \\
\hline 3 & 3 & 4 & 2 & 2.38 & 0.68 & 0.15 & 0.31 & 1.81 & 0.88 & 0.29 & 0.29 & 24 \\
\hline 3 & 3 & 4 & 3 & 2.52 & 0.56 & 0.23 & 0.36 & 1.88 & 0.84 & 0.25 & 0.39 & 24 \\
\hline 4 & 1 & 0 & 1 & 3.27 & 0.71 & 0.00 & 0.00 & 0 & 0 & 0.08 & 0.19 & 24 \\
\hline 4 & 1 & 0 & 2 & 3.23 & 0.63 & 0.00 & 0.00 & 0 & 0 & 0.15 & 0.23 & 24 \\
\hline 4 & 1 & 0 & 3 & 3.25 & 0.72 & 0.08 & 0.19 & 0 & 0 & 0.27 & 0.33 & 24 \\
\hline 4 & 1 & 1 & 1 & 3.15 & 0.56 & 0.13 & 0.22 & 0.85 & 0.23 & 0.08 & 0.19 & 24 \\
\hline 4 & 1 & 1 & 2 & 2.92 & 0.72 & 0.02 & 0.10 & 0.9 & 0.25 & 0.17 & 0.28 & 24 \\
\hline 4 & 1 & 1 & 3 & 2.88 & 0.54 & 0.06 & 0.17 & 0.81 & 0.25 & 0.21 & 0.29 & 24 \\
\hline 4 & 1 & 2 & 1 & 3.02 & 0.63 & 0.06 & 0.17 & 1.48 & 0.5 & 0.00 & 0.00 & 24 \\
\hline 4 & 1 & 2 & 2 & 2.96 & 0.85 & 0.08 & 0.19 & 1.6 & 0.59 & 0.13 & 0.22 & 24 \\
\hline 4 & 1 & 2 & 3 & 2.79 & 0.82 & 0.10 & 0.21 & 1.52 & 0.52 & 0.23 & 0.42 & 24 \\
\hline 4 & 1 & 3 & 1 & 2.98 & 0.71 & 0.06 & 0.17 & 1.83 & 0.67 & 0.08 & 0.19 & 24 \\
\hline 4 & 1 & 3 & 2 & 2.81 & 0.82 & 0.02 & 0.10 & 1.85 & 0.56 & 0.23 & 0.33 & 24 \\
\hline 4 & 1 & 3 & 3 & 3.02 & 0.9 & 0.15 & 0.23 & 1.75 & 0.64 & 0.10 & 0.21 & 24 \\
\hline 4 & 1 & 4 & 1 & 2.88 & 0.65 & 0.10 & 0.21 & 2.17 & 0.72 & 0.10 & 0.25 & 24 \\
\hline 4 & 1 & 4 & 2 & 2.88 & 0.77 & 0.10 & 0.21 & 2.02 & 0.63 & 0.21 & 0.25 & 24 \\
\hline 4 & 1 & 4 & 3 & 3.06 & 0.65 & 0.04 & 0.14 & 1.65 & 0.93 & 0.19 & 0.25 & 24 \\
\hline 4 & 2 & 0 & 1 & 3.17 & 0.6 & 0.10 & 0.29 & 0 & 0 & 0.10 & 0.21 & 24 \\
\hline 4 & 2 & 0 & 2 & 2.92 & 0.7 & 0.13 & 0.27 & 0 & 0 & 0.21 & 0.33 & 24 \\
\hline 4 & 2 & 0 & 3 & 3.02 & 0.63 & 0.06 & 0.17 & 0 & 0 & 0.21 & 0.33 & 24 \\
\hline 4 & 2 & 1 & 1 & 2.96 & 0.87 & 0.13 & 0.22 & 0.85 & 0.23 & 0.10 & 0.21 & 24 \\
\hline
\end{tabular}


Table 1 (continued)

\begin{tabular}{|c|c|c|c|c|c|c|c|c|c|c|c|c|}
\hline \multicolumn{2}{|c|}{$\begin{array}{l}\text { Display } 1 \\
\text { Presentation }\end{array}$} & \multicolumn{2}{|c|}{$\begin{array}{l}\text { Display } 2 \\
\text { Presentation }\end{array}$} & \multicolumn{4}{|c|}{ Display 1 Report } & \multicolumn{4}{|c|}{ Display 2 Report } & \multirow[b]{2}{*}{$N$} \\
\hline Targets & Distractors & Targets & Distractors & $\begin{array}{l}\text { Mean } \\
\text { Targets }\end{array}$ & $\begin{array}{l}S D \\
\text { Targets }\end{array}$ & $\begin{array}{l}\text { Mean } \\
\text { Distractors }\end{array}$ & $\begin{array}{l}S D \\
\text { Distractors }\end{array}$ & $\begin{array}{l}\text { Mean } \\
\text { Targets }\end{array}$ & $\begin{array}{l}S D \\
\text { Targets }\end{array}$ & $\begin{array}{l}\text { Mean } \\
\text { Distractors }\end{array}$ & $\begin{array}{l}S D \\
\text { Distractors }\end{array}$ & \\
\hline 4 & 2 & 1 & 2 & 2.92 & 0.69 & 0.04 & 0.14 & 0.83 & 0.24 & 0.15 & 0.28 & 24 \\
\hline 4 & 2 & 1 & 3 & 3.04 & 0.72 & 0.15 & 0.23 & 0.85 & 0.28 & 0.19 & 0.32 & 24 \\
\hline 4 & 2 & 2 & 1 & 3.06 & 0.77 & 0.15 & 0.28 & 1.52 & 0.48 & 0.08 & 0.19 & 24 \\
\hline 4 & 2 & 2 & 2 & 3.08 & 0.73 & 0.19 & 0.29 & 1.44 & 0.47 & 0.13 & 0.22 & 24 \\
\hline 4 & 2 & 2 & 3 & 3 & 0.74 & 0.10 & 0.21 & 1.25 & 0.61 & 0.29 & 0.36 & 24 \\
\hline 4 & 2 & 3 & 1 & 2.9 & 0.72 & 0.15 & 0.28 & 1.92 & 0.65 & 0.04 & 0.14 & 24 \\
\hline 4 & 2 & 3 & 2 & 2.83 & 0.72 & 0.08 & 0.24 & 1.83 & 0.76 & 0.13 & 0.30 & 24 \\
\hline 4 & 2 & 3 & 3 & 3.08 & 0.75 & 0.13 & 0.22 & 1.54 & 0.72 & 0.25 & 0.36 & 24 \\
\hline 4 & 2 & 4 & 1 & 2.71 & 0.81 & 0.25 & 0.33 & 2 & 0.72 & 0.04 & 0.14 & 24 \\
\hline 4 & 2 & 4 & 2 & 2.88 & 0.78 & 0.13 & 0.22 & 2.1 & 0.74 & 0.08 & 0.19 & 24 \\
\hline 4 & 2 & 4 & 3 & 2.96 & 0.59 & 0.06 & 0.17 & 1.75 & 0.83 & 0.31 & 0.32 & 24 \\
\hline 4 & 3 & 0 & 1 & 3.13 & 0.77 & 0.10 & 0.25 & 0 & 0 & 0.08 & 0.19 & 24 \\
\hline 4 & 3 & 0 & 2 & 3.02 & 0.52 & 0.19 & 0.29 & 0 & 0 & 0.10 & 0.29 & 24 \\
\hline 4 & 3 & 0 & 3 & 3.21 & 0.76 & 0.21 & 0.39 & 0 & 0 & 0.21 & 0.33 & 24 \\
\hline 4 & 3 & 1 & 1 & 3.1 & 0.72 & 0.19 & 0.29 & 0.75 & 0.36 & 0.08 & 0.19 & 24 \\
\hline 4 & 3 & 1 & 2 & 3.06 & 0.63 & 0.17 & 0.35 & 0.81 & 0.25 & 0.13 & 0.27 & 24 \\
\hline 4 & 3 & 1 & 3 & 2.85 & 0.79 & 0.33 & 0.38 & 0.79 & 0.36 & 0.13 & 0.27 & 24 \\
\hline 4 & 3 & 2 & 1 & 2.77 & 1.08 & 0.21 & 0.25 & 1.65 & 0.38 & 0.08 & 0.19 & 24 \\
\hline 4 & 3 & 2 & 2 & 2.79 & 0.82 & 0.17 & 0.24 & 1.67 & 0.46 & 0.08 & 0.24 & 24 \\
\hline 4 & 3 & 2 & 3 & 2.98 & 0.71 & 0.19 & 0.29 & 1.38 & 0.65 & 0.29 & 0.33 & 24 \\
\hline 4 & 3 & 3 & 1 & 2.46 & 0.85 & 0.17 & 0.24 & 1.85 & 0.58 & 0.15 & 0.28 & 24 \\
\hline 4 & 3 & 3 & 2 & 2.63 & 0.84 & 0.27 & 0.29 & 1.75 & 0.71 & 0.19 & 0.32 & 24 \\
\hline 4 & 3 & 3 & 3 & 2.73 & 0.9 & 0.08 & 0.19 & 1.73 & 0.71 & 0.27 & 0.36 & 24 \\
\hline 4 & 3 & 4 & 1 & 2.83 & 0.89 & 0.15 & 0.23 & 1.79 & 0.72 & 0.06 & 0.17 & 24 \\
\hline 4 & 3 & 4 & 2 & 2.83 & 0.76 & 0.10 & 0.21 & 1.96 & 0.87 & 0.17 & 0.28 & 24 \\
\hline 4 & 3 & 4 & 3 & 2.88 & 0.63 & 0.21 & 0.36 & 1.85 & 0.6 & 0.23 & 0.25 & 24 \\
\hline
\end{tabular}

Target and distractor report are shown for both displays

Table 2 ANOVA effects in Experiment 1

\begin{tabular}{|c|c|c|c|c|c|c|c|c|}
\hline \multirow[b]{2}{*}{ Effect } & \multicolumn{4}{|c|}{ Display 1 Targets Reported } & \multicolumn{4}{|c|}{ Display 2 Targets Reported } \\
\hline & $d f$ & $\begin{array}{l}\text { Mean Squared } \\
\text { Error }\end{array}$ & $F$ & $\begin{array}{l}\text { Partial Eta } \\
\text { Squared }\end{array}$ & $d f$ & $\begin{array}{l}\text { Mean Squared } \\
\text { Error }\end{array}$ & $F$ & $\begin{array}{l}\text { Partial Eta } \\
\text { Squared }\end{array}$ \\
\hline $\mathrm{D} 1 \mathrm{~T}$ & 4 & $1,568.34$ & $822.97^{* * * *}$ & .97 & 4 & 27.94 & $74.76^{* * * *}$ & .77 \\
\hline Error(D1T) & 92 & 1.91 & & & 92 & 0.37 & & \\
\hline D1D & 2 & 0.71 & 2.88 & .11 & 2 & 0.16 & 0.59 & .03 \\
\hline Error(D1D) & 46 & 0.25 & & & 46 & 0.27 & & \\
\hline $\mathrm{D} 2 \mathrm{~T}$ & 4 & 2.08 & $12.40^{* * * *}$ & .35 & 4 & $1,012.91$ & $433.86^{* * * *}$ & .95 \\
\hline Error(D2T) & 92 & 0.17 & & & 92 & 2.34 & & \\
\hline $\mathrm{D} 2 \mathrm{D}$ & 2 & 0.14 & 1.18 & .05 & 2 & 1.58 & $8.29^{* * *}$ & .27 \\
\hline Error(D2D) & 46 & 0.12 & & & 46 & 0.19 & & \\
\hline $\mathrm{D} 1 \mathrm{~T} \times \mathrm{D} 1 \mathrm{D}$ & 8 & 0.23 & 1.54 & .06 & 8 & 0.18 & 1.25 & .05 \\
\hline Error(D1T×D1D) & 184 & 0.15 & & & 184 & 0.14 & & \\
\hline
\end{tabular}


Table 2 (continued)

\begin{tabular}{|c|c|c|c|c|c|c|c|c|}
\hline \multirow[b]{2}{*}{ Effect } & \multicolumn{4}{|c|}{ Display 1 Targets Reported } & \multicolumn{4}{|c|}{ Display 2 Targets Reported } \\
\hline & $d f$ & $\begin{array}{l}\text { Mean Squared } \\
\text { Error }\end{array}$ & $F$ & $\begin{array}{l}\text { Partial Eta } \\
\text { Squared }\end{array}$ & $d f$ & $\begin{array}{l}\text { Mean Squared } \\
\text { Error }\end{array}$ & $F$ & $\begin{array}{l}\text { Partial Eta } \\
\text { Squared }\end{array}$ \\
\hline $\mathrm{D} 1 \mathrm{~T} \times \mathrm{D} 2 \mathrm{~T}$ & 16 & 0.51 & $4.24^{* * * *}$ & .16 & 16 & 5.19 & $28.99^{* * *}$ & .56 \\
\hline Error(D1T×D2T) & 368 & 0.12 & & & 368 & 0.18 & & \\
\hline $\mathrm{D} 1 \mathrm{D} \times \mathrm{D} 2 \mathrm{~T}$ & 8 & 0.26 & 1.74 & .07 & 8 & 0.26 & 1.15 & .05 \\
\hline Error(D1D×D2T) & 184 & 0.15 & & & 184 & 0.23 & & \\
\hline $\mathrm{D} 1 \mathrm{~T} \times \mathrm{D} 1 \mathrm{D} \times \mathrm{D} 2 \mathrm{~T}$ & 32 & 0.20 & $1.53^{*}$ & .06 & 32 & 0.14 & 0.91 & .04 \\
\hline Error(D1T×D1D×D2T) & 736 & 0.13 & & & 736 & 0.15 & & \\
\hline $\mathrm{D} 1 \mathrm{~T} \times \mathrm{D} 2 \mathrm{D}$ & 8 & 0.23 & $2.06^{*}$ & .08 & 8 & 0.47 & $3.51^{* * * *}$ & .13 \\
\hline Error(D1T×D2D) & 184 & 0.11 & & & 184 & 0.13 & & \\
\hline $\mathrm{D} 1 \mathrm{D} \times \mathrm{D} 2 \mathrm{D}$ & 4 & 0.14 & 1.32 & .05 & 4 & 0.04 & 0.32 & .01 \\
\hline Error(D1D×D2D) & 92 & 0.11 & & & 92 & 0.13 & & \\
\hline $\mathrm{D} 1 \mathrm{~T} \times \mathrm{D} 1 \mathrm{D} \times \mathrm{D} 2 \mathrm{D}$ & 16 & 0.11 & 1.21 & .05 & 16 & 0.15 & 0.93 & .04 \\
\hline Error(D1T×D1D×D2D) & 368 & 0.09 & & & 368 & 0.16 & & \\
\hline $\mathrm{D} 2 \mathrm{~T} \times \mathrm{D} 2 \mathrm{D}$ & 8 & 0.16 & 1.14 & .05 & 8 & 0.51 & $3.14^{* *}$ & .12 \\
\hline Error(D2T×D2D) & 184 & 0.14 & & & 184 & 0.16 & & \\
\hline $\mathrm{D} 1 \mathrm{~T} \times \mathrm{D} 2 \mathrm{~T} \times \mathrm{D} 2 \mathrm{D}$ & 32 & 0.11 & 0.75 & .03 & 32 & 0.22 & $1.51^{*}$ & .06 \\
\hline Error(D1T×D2T×D2D) & 736 & 0.14 & & & 736 & 0.15 & & \\
\hline $\mathrm{D} 1 \mathrm{D} \times \mathrm{D} 2 \mathrm{~T} \times \mathrm{D} 2 \mathrm{D}$ & 16 & 0.11 & 0.88 & .04 & 16 & 0.18 & 1.09 & .05 \\
\hline Error(D1D×D2T×D2D) & 368 & 0.13 & & & 368 & 0.16 & & \\
\hline $\mathrm{D} 1 \mathrm{~T} \times \mathrm{D} 1 \mathrm{D} \times \mathrm{D} 2 \mathrm{~T} \times \mathrm{D} 2 \mathrm{D}$ & 64 & 0.12 & 0.99 & .04 & 64 & 0.12 & 0.81 & .03 \\
\hline Error(D1T×D1D×D2T×D2D) & 1,472 & 0.12 & & & 1,472 & 0.15 & & \\
\hline
\end{tabular}

${ }^{*}$ Significant at $\alpha=.05 .{ }^{* *}$ Significant at $\alpha=.01 .{ }^{* * * *}$ Significant at $\alpha=.001$. D1T: Display 1 targets. D1D: Display 1 distractors. D2T: Display 2 targets. D2D: Display 2 distractors. Effects are shown for target report in both displays

\section{Appendix B: Experiment 2 descriptive statistics and ANOVA output tables}

Table 3 Descriptive statistics for each trial type in Experiment 2

\begin{tabular}{|c|c|c|c|c|c|c|c|c|c|c|c|c|}
\hline \multicolumn{2}{|c|}{$\begin{array}{l}\text { Display } 1 \\
\text { Presentation }\end{array}$} & \multicolumn{2}{|c|}{$\begin{array}{l}\text { Display } 2 \\
\text { Presentation }\end{array}$} & \multicolumn{4}{|c|}{ Display 1 Report } & \multicolumn{4}{|c|}{ Display 2 Report } & \multirow[b]{2}{*}{$N$} \\
\hline Targets & Distractors & Targets & Distractors & $\begin{array}{l}\text { Mean } \\
\text { Targets }\end{array}$ & $\begin{array}{l}S D \\
\text { Targets }\end{array}$ & $\begin{array}{l}\text { Mean } \\
\text { Distractors }\end{array}$ & $\begin{array}{l}S D \\
\text { Distractors }\end{array}$ & $\begin{array}{l}\text { Mean } \\
\text { Targets }\end{array}$ & $\begin{array}{l}S D \\
\text { Targets }\end{array}$ & $\begin{array}{l}\text { Mean } \\
\text { Distractors }\end{array}$ & $\begin{array}{l}S D \\
\text { Distractors }\end{array}$ & \\
\hline 1 & 1 & 1 & 1 & 0.88 & 0.11 & 0.07 & 0.06 & 0.88 & 0.12 & 0.08 & 0.07 & 24 \\
\hline 1 & 1 & 1 & 4 & 0.88 & 0.11 & 0.06 & 0.05 & 0.76 & 0.19 & 0.49 & 0.33 & 24 \\
\hline 1 & 1 & 4 & 1 & 0.88 & 0.10 & 0.07 & 0.09 & 2.15 & 0.60 & 0.05 & 0.06 & 24 \\
\hline 1 & 1 & 4 & 4 & 0.86 & 0.11 & 0.06 & 0.05 & 1.96 & 0.59 & 0.19 & 0.14 & 24 \\
\hline 1 & 4 & 1 & 1 & 0.85 & 0.13 & 0.51 & 0.32 & 0.85 & 0.11 & 0.08 & 0.08 & 24 \\
\hline 1 & 4 & 1 & 4 & 0.83 & 0.16 & 0.50 & 0.36 & 0.76 & 0.19 & 0.43 & 0.23 & 24 \\
\hline 1 & 4 & 4 & 1 & 0.80 & 0.16 & 0.58 & 0.35 & 2.10 & 0.61 & 0.06 & 0.06 & 24 \\
\hline 1 & 4 & 4 & 4 & 0.78 & 0.17 & 0.53 & 0.29 & 1.90 & 0.57 & 0.19 & 0.15 & 24 \\
\hline 4 & 1 & 1 & 1 & 2.40 & 0.62 & 0.05 & 0.09 & 0.83 & 0.14 & 0.08 & 0.07 & 24 \\
\hline 4 & 1 & 1 & 4 & 2.42 & 0.62 & 0.06 & 0.06 & 0.73 & 0.15 & 0.45 & 0.20 & 24 \\
\hline 4 & 1 & 4 & 1 & 2.32 & 0.67 & 0.05 & 0.05 & 1.95 & 0.60 & 0.05 & 0.06 & 24 \\
\hline 4 & 1 & 4 & 4 & 2.42 & 0.61 & 0.07 & 0.09 & 1.73 & 0.57 & 0.24 & 0.12 & 24 \\
\hline
\end{tabular}


Table 3 (continued)

\begin{tabular}{|c|c|c|c|c|c|c|c|c|c|c|c|c|}
\hline \multicolumn{2}{|c|}{$\begin{array}{l}\text { Display } 1 \\
\text { Presentation }\end{array}$} & \multicolumn{2}{|c|}{$\begin{array}{l}\text { Display } 2 \\
\text { Presentation }\end{array}$} & \multicolumn{4}{|c|}{ Display 1 Report } & \multicolumn{4}{|c|}{ Display 2 Report } & \multirow[b]{2}{*}{$N$} \\
\hline Targets & Distractors & Targets & Distractors & $\begin{array}{l}\text { Mean } \\
\text { Targets }\end{array}$ & $\begin{array}{l}S D \\
\text { Targets }\end{array}$ & $\begin{array}{l}\text { Mean } \\
\text { Distractors }\end{array}$ & $\begin{array}{l}S D \\
\text { Distractors }\end{array}$ & $\begin{array}{l}\text { Mean } \\
\text { Targets }\end{array}$ & $\begin{array}{l}S D \\
\text { Targets }\end{array}$ & $\begin{array}{l}\text { Mean } \\
\text { Distractors }\end{array}$ & $\begin{array}{l}S D \\
\text { Distractors }\end{array}$ & \\
\hline 4 & 4 & 1 & 1 & 2.36 & 0.72 & 0.23 & 0.15 & 0.83 & 0.13 & 0.08 & 0.06 & 24 \\
\hline 4 & 4 & 1 & 4 & 2.38 & 0.72 & 0.23 & 0.18 & 0.73 & 0.17 & 0.43 & 0.23 & 24 \\
\hline 4 & 4 & 4 & 1 & 2.33 & 0.60 & 0.23 & 0.22 & 1.85 & 0.54 & 0.06 & 0.07 & 24 \\
\hline 4 & 4 & 4 & 4 & 2.33 & 0.60 & 0.22 & 0.12 & 1.70 & 0.53 & 0.21 & 0.14 & 24 \\
\hline
\end{tabular}

Target and distractor report are shown for both displays

Table 4 ANOVA effects in Experiment 2

\begin{tabular}{|c|c|c|c|c|c|c|c|c|}
\hline \multirow[b]{2}{*}{ Effect } & \multicolumn{4}{|c|}{ Display 1 Targets Reported } & \multicolumn{4}{|c|}{ Display 2 Targets Reported } \\
\hline & $d f$ & Mean Squared Error & $F$ & Partial Eta Squared & $d f$ & Mean Squared Error & $F$ & Partial Eta Squared \\
\hline D1T & 1 & 223.06 & $193.81^{* * * *}$ & .89 & 1 & 1.45 & $36.59^{* * * * *}$ & .61 \\
\hline Error(D1T) & 23 & 1.15 & & & 23 & 0.04 & & \\
\hline D1D & 1 & 0.23 & $4.97^{*}$ & .18 & 1 & 0.10 & $5.95^{*}$ & .21 \\
\hline Error(D1D) & 23 & 0.05 & & & 23 & 0.02 & & \\
\hline $\mathrm{D} 2 \mathrm{~T}$ & 1 & 0.11 & $5.81^{*}$ & .20 & 1 & 120.68 & $146.54^{* * *}$ & .86 \\
\hline Error(D2T) & 23 & 0.02 & & & 23 & 0.82 & & \\
\hline D2D & 1 & 0.01 & 0.85 & .04 & 1 & 2.02 & $92.78^{* * * *}$ & .80 \\
\hline Error(D2D) & 23 & 0.01 & & & 23 & 0.02 & & \\
\hline $\mathrm{D} 1 \mathrm{~T} \times \mathrm{D} 1 \mathrm{D}$ & 1 & 0.01 & 0.45 & .02 & 1 & 0.00 & 0.00 & .00 \\
\hline Error(D1T×D1D) & 23 & 0.03 & & & 23 & 0.01 & & \\
\hline $\mathrm{D} 1 \mathrm{~T} \times \mathrm{D} 2 \mathrm{~T}$ & 1 & 0.00 & 0.04 & .00 & 1 & 0.87 & $27.99^{* * * *}$ & .55 \\
\hline Error(D1T×D2T) & 23 & 0.02 & & & 23 & 0.03 & & \\
\hline $\mathrm{D} 1 \mathrm{D} \times \mathrm{D} 2 \mathrm{~T}$ & 1 & 0.01 & 0.30 & .01 & 1 & 0.07 & 3.31 & .13 \\
\hline Error(D1D×D2T) & 23 & 0.02 & & & 23 & 0.02 & & \\
\hline $\mathrm{D} 1 \mathrm{~T} \times \mathrm{D} 1 \mathrm{D} \times \mathrm{D} 2 \mathrm{~T}$ & 1 & 0.01 & 0.43 & .02 & 1 & 0.00 & 0.34 & .01 \\
\hline Error(D1T×D1D×D2T) & 23 & 0.02 & & & 23 & 0.01 & & \\
\hline $\mathrm{D} 1 \mathrm{~T} \times \mathrm{D} 2 \mathrm{D}$ & 1 & 0.06 & $7.79^{*}$ & .25 & 1 & 0.00 & 0.09 & .00 \\
\hline Error(D1T×D2D) & 23 & 0.01 & & & 23 & 0.01 & & \\
\hline $\mathrm{D} 1 \mathrm{D} \times \mathrm{D} 2 \mathrm{D}$ & 1 & 0.02 & 0.70 & .03 & 1 & 0.01 & 0.51 & .02 \\
\hline Error(D1D×D2D) & 23 & 0.02 & & & 23 & 0.02 & & \\
\hline $\mathrm{D} 1 \mathrm{~T} \times \mathrm{D} 1 \mathrm{D} \times \mathrm{D} 2 \mathrm{D}$ & 1 & 0.01 & 0.58 & .03 & 1 & 0.00 & 0.41 & .02 \\
\hline Error(D1T×D1D×D2D) & 23 & 0.02 & & & 23 & 0.01 & & \\
\hline $\mathrm{D} 2 \mathrm{~T} \times \mathrm{D} 2 \mathrm{D}$ & 1 & 0.00 & 0.22 & .01 & 1 & 0.16 & $8.82^{* *}$ & .28 \\
\hline Error(D2T×D2D) & 23 & 0.02 & & & 23 & 0.02 & & \\
\hline $\mathrm{D} 1 \mathrm{~T} \times \mathrm{D} 2 \mathrm{~T} \times \mathrm{D} 2 \mathrm{D}$ & 1 & 0.01 & 0.32 & .01 & 1 & 0.00 & 0.01 & .00 \\
\hline Error(D1T×D2T×D2D) & 23 & 0.02 & & & 23 & 0.01 & & \\
\hline $\mathrm{D} 1 \mathrm{D} \times \mathrm{D} 2 \mathrm{~T} \times \mathrm{D} 2 \mathrm{D}$ & 1 & 0.01 & 0.59 & .03 & 1 & 0.00 & 0.19 & .01 \\
\hline Error(D1D×D2T×D2D) & 23 & 0.01 & & & 23 & 0.02 & & \\
\hline $\mathrm{D} 1 \mathrm{~T} \times \mathrm{D} 1 \mathrm{D} \times \mathrm{D} 2 \mathrm{~T} \times \mathrm{D} 2 \mathrm{D}$ & 1 & 0.02 & 2.60 & .10 & 1 & 0.01 & 1.68 & .07 \\
\hline Error $(\mathrm{D} 1 \mathrm{~T} \times \mathrm{D} 1 \mathrm{D} \times \mathrm{D} 2 \mathrm{~T} \times \mathrm{D} 2 \mathrm{D})$ & 23 & 0.01 & & & 23 & 0.01 & & \\
\hline
\end{tabular}

${ }^{*}$ Significant at $\alpha=.05{ }^{* * *}$ Significant at $\alpha=.01{ }^{* * * *}$ Significant at $\alpha=.001$. D1T: Display 1 targets. D1D: Display 1 distractors. D2T: Display 2 targets. D2D: Display 2 distractors. Effects are shown for target report in both displays 


\section{Appendix C: Experiment 3 descriptive statistics and ANOVA output tables}

Table 5 Descriptive statistics for each trial type in Experiment 3

\begin{tabular}{|c|c|c|c|c|c|c|c|c|c|c|c|c|}
\hline \multicolumn{2}{|c|}{$\begin{array}{l}\text { Display } 1 \\
\text { Presentation }\end{array}$} & \multicolumn{2}{|c|}{$\begin{array}{l}\text { Display } 2 \\
\text { Presentation }\end{array}$} & \multicolumn{4}{|c|}{ Display 1 Report } & \multicolumn{4}{|c|}{ Display 2 Report } & \multirow[b]{2}{*}{$N$} \\
\hline Targets & Distractors & Targets & Distractors & $\begin{array}{l}\text { Mean } \\
\text { Targets }\end{array}$ & $\begin{array}{l}S D \\
\text { Targets }\end{array}$ & $\begin{array}{l}\text { Mean } \\
\text { Distractors }\end{array}$ & $\begin{array}{l}S D \\
\text { Distractors }\end{array}$ & $\begin{array}{l}\text { Mean } \\
\text { Targets }\end{array}$ & $\begin{array}{l}S D \\
\text { Targets }\end{array}$ & $\begin{array}{l}\text { Mean } \\
\text { Distractors }\end{array}$ & $\begin{array}{l}S D \\
\text { Distractors }\end{array}$ & \\
\hline 1 & 1 & 1 & 1 & 0.81 & 0.16 & 0.15 & 0.18 & 0.82 & 0.13 & 0.17 & 0.19 & 24 \\
\hline 1 & 1 & 1 & 4 & 0.80 & 0.17 & 0.13 & 0.16 & 0.64 & 0.15 & 0.56 & 0.38 & 24 \\
\hline 1 & 1 & 4 & 1 & 0.81 & 0.16 & 0.15 & 0.18 & 1.70 & 0.38 & 0.09 & 0.12 & 24 \\
\hline 1 & 1 & 4 & 4 & 0.78 & 0.20 & 0.16 & 0.16 & 1.43 & 0.42 & 0.29 & 0.28 & 24 \\
\hline 1 & 4 & 1 & 1 & 0.75 & 0.18 & 0.55 & 0.47 & 0.81 & 0.17 & 0.16 & 0.20 & 24 \\
\hline 1 & 4 & 1 & 4 & 0.70 & 0.14 & 0.61 & 0.45 & 0.63 & 0.13 & 0.51 & 0.35 & 24 \\
\hline 1 & 4 & 4 & 1 & 0.65 & 0.17 & 0.60 & 0.46 & 1.62 & 0.39 & 0.08 & 0.08 & 24 \\
\hline 1 & 4 & 4 & 4 & 0.72 & 0.16 & 0.64 & 0.47 & 1.44 & 0.32 & 0.26 & 0.24 & 24 \\
\hline 4 & 1 & 1 & 1 & 1.83 & 0.45 & 0.08 & 0.09 & 0.75 & 0.16 & 0.19 & 0.22 & 24 \\
\hline 4 & 1 & 1 & 4 & 1.80 & 0.44 & 0.10 & 0.12 & 0.61 & 0.17 & 0.52 & 0.37 & 24 \\
\hline 4 & 1 & 4 & 1 & 1.76 & 0.45 & 0.11 & 0.10 & 1.46 & 0.32 & 0.10 & 0.09 & 24 \\
\hline 4 & 1 & 4 & 4 & 1.78 & 0.45 & 0.09 & 0.09 & 1.29 & 0.35 & 0.27 & 0.21 & 24 \\
\hline 4 & 4 & 1 & 1 & 1.70 & 0.40 & 0.27 & 0.25 & 0.77 & 0.14 & 0.18 & 0.18 & 24 \\
\hline 4 & 4 & 1 & 4 & 1.70 & 0.42 & 0.24 & 0.21 & 0.61 & 0.17 & 0.53 & 0.36 & 24 \\
\hline 4 & 4 & 4 & 1 & 1.62 & 0.43 & 0.33 & 0.30 & 1.48 & 0.34 & 0.07 & 0.09 & 24 \\
\hline 4 & 4 & 4 & 4 & 1.70 & 0.35 & 0.33 & 0.24 & 1.22 & 0.35 & 0.30 & 0.27 & 24 \\
\hline
\end{tabular}

Target and distractor report are shown for both displays

Table 6 ANOVA effects in Experiment 3

\begin{tabular}{|c|c|c|c|c|c|c|c|c|}
\hline \multirow[b]{2}{*}{ Effect } & \multicolumn{4}{|c|}{ Display 1 Targets Reported } & \multicolumn{4}{|c|}{ Display 2 Targets Reported } \\
\hline & $d f$ & Mean Squared Error & $F$ & Partial Eta Squared & $d f$ & Mean Squared Error & $F$ & Partial Eta Squared \\
\hline D1T & 1 & 93.25 & $198.80^{* * * *}$ & 0.90 & 1 & 1.25 & $41.68^{* * *}$ & 0.64 \\
\hline Error(D1T) & 23 & 0.47 & & & 23 & 0.03 & & \\
\hline D1D & 1 & 1.07 & $9.30^{* *}$ & 0.29 & 1 & 0.03 & 1.59 & 0.07 \\
\hline Error(D1D) & 23 & 0.12 & & & 23 & 0.02 & & \\
\hline $\mathrm{D} 2 \mathrm{~T}$ & 1 & 0.11 & $8.24^{* *}$ & 0.26 & 1 & 54.20 & $179.70^{* * *}$ & 0.89 \\
\hline Error(D2T) & 23 & 0.01 & & & 23 & 0.30 & & \\
\hline $\mathrm{D} 2 \mathrm{D}$ & 1 & 0.00 & 0.18 & 0.01 & 1 & 3.51 & $55.19^{* * * *}$ & 0.71 \\
\hline Error(D2D) & 23 & 0.02 & & & 23 & 0.06 & & \\
\hline $\mathrm{D} 1 \mathrm{~T} \times \mathrm{D} 1 \mathrm{D}$ & 1 & 0.01 & 0.25 & 0.01 & 1 & 0.00 & 0.28 & 0.01 \\
\hline Error(D1T×D1D) & 23 & 0.03 & & & 23 & 0.02 & & \\
\hline $\mathrm{D} 1 \mathrm{~T} \times \mathrm{D} 2 \mathrm{~T}$ & 1 & 0.01 & 0.44 & 0.02 & 1 & 0.51 & $34.97^{* * * *}$ & 0.60 \\
\hline Error(D1T×D2T) & 23 & 0.02 & & & 23 & 0.02 & & \\
\hline $\mathrm{D} 1 \mathrm{D} \times \mathrm{D} 2 \mathrm{~T}$ & 1 & 0.00 & 0.13 & 0.01 & 1 & 0.03 & 1.88 & 0.08 \\
\hline Error(D1D×D2T) & 23 & 0.01 & & & 23 & 0.02 & & \\
\hline $\mathrm{D} 1 \mathrm{~T} \times \mathrm{D} 1 \mathrm{D} \times \mathrm{D} 2 \mathrm{~T}$ & 1 & 0.01 & 0.59 & 0.03 & 1 & 0.00 & 0.02 & 0.00 \\
\hline Error(D1T×D1D×D2T) & 23 & 0.01 & & & 23 & 0.01 & & \\
\hline $\mathrm{D} 1 \mathrm{~T} \times \mathrm{D} 2 \mathrm{D}$ & 1 & 0.01 & 0.57 & 0.02 & 1 & 0.01 & 0.63 & 0.03 \\
\hline Error(D1T×D2D) & 23 & 0.01 & & & 23 & 0.02 & & \\
\hline
\end{tabular}


Table 6 (continued)

\begin{tabular}{|c|c|c|c|c|c|c|c|c|}
\hline \multirow[b]{2}{*}{ Effect } & \multicolumn{4}{|c|}{ Display 1 Targets Reported } & \multicolumn{4}{|c|}{ Display 2 Targets Reported } \\
\hline & $d f$ & Mean Squared Error & $F$ & Partial Eta Squared & $d f$ & Mean Squared Error & $F$ & Partial Eta Squared \\
\hline $\mathrm{D} 1 \mathrm{D} \times \mathrm{D} 2 \mathrm{D}$ & 1 & 0.02 & 1.26 & 0.05 & 1 & 0.00 & 0.18 & 0.01 \\
\hline Error(D1D×D2D) & 23 & 0.02 & & & 23 & 0.01 & & \\
\hline $\mathrm{D} 1 \mathrm{~T} \times \mathrm{D} 1 \mathrm{D} \times \mathrm{D} 2 \mathrm{D}$ & 1 & 0.00 & 0.12 & 0.01 & 1 & 0.06 & 3.53 & 0.13 \\
\hline Error(D1T×D1D×D2D) & 23 & 0.02 & & & 23 & 0.02 & & \\
\hline $\mathrm{D} 2 \mathrm{~T} \times \mathrm{D} 2 \mathrm{D}$ & 1 & 0.08 & 9.43 & 0.29 & 1 & 0.07 & 3.81 & 0.14 \\
\hline Error(D2T×D2D) & 23 & 0.01 & & & 23 & 0.02 & & \\
\hline $\mathrm{D} 1 \mathrm{~T} \times \mathrm{D} 2 \mathrm{~T} \times \mathrm{D} 2 \mathrm{D}$ & 1 & 0.00 & 0.13 & 0.01 & 1 & 0.00 & 0.07 & 0.00 \\
\hline Error(D1T×D2T×D2D) & 23 & 0.01 & & & 23 & 0.02 & & \\
\hline $\mathrm{D} 1 \mathrm{D} \times \mathrm{D} 2 \mathrm{~T} \times \mathrm{D} 2 \mathrm{D}$ & 1 & 0.04 & 2.90 & 0.11 & 1 & 0.00 & 0.02 & 0.00 \\
\hline Error(D1D×D2T×D2D) & 23 & 0.01 & & & 23 & 0.02 & & \\
\hline $\mathrm{D} 1 \mathrm{~T} \times \mathrm{D} 1 \mathrm{D} \times \mathrm{D} 2 \mathrm{~T} \times \mathrm{D} 2 \mathrm{D}$ & 1 & 0.02 & 1.00 & 0.04 & 1 & 0.04 & 1.88 & 0.08 \\
\hline Error(D1T×D1D×D2T×D2D) & 23 & 0.02 & & & 23 & 0.02 & & \\
\hline
\end{tabular}

${ }^{*}$ Significant at $\alpha=.05{ }^{* *}$ Significant at $\alpha=.01 .^{* * *}$ Significant at $\alpha=.001$. D1T: Display 1 targets. D1D: Display 1 distractors. D2T: Display 2 targets. D2D: Display 2 distractors. Effects are shown for target report in both displays

\section{Appendix D: Experiment 4 descriptive statistics and ANOVA output tables}

Table 7 Descriptive statistics for each trial type in Experiment 4

\begin{tabular}{|c|c|c|c|c|c|c|c|c|}
\hline \multicolumn{2}{|c|}{ Display 1 Presentation } & \multicolumn{2}{|c|}{ Display 2 Presentation } & \multicolumn{2}{|c|}{ Display $1 K$} & \multicolumn{2}{|c|}{ Display $2 K$} & \multirow[b]{2}{*}{$N$} \\
\hline Targets & Distractors & Targets & Distractors & Mean $K$ & $S D K$ & Mean $K$ & $S D K$ & \\
\hline 1 & 1 & 1 & 1 & 0.86 & 0.15 & 0.91 & 0.12 & 24 \\
\hline 1 & 1 & 1 & 4 & 0.88 & 0.12 & 0.86 & 0.13 & 24 \\
\hline 1 & 1 & 4 & 1 & 0.84 & 0.16 & 1.74 & 0.74 & 24 \\
\hline 1 & 1 & 4 & 4 & 0.89 & 0.14 & 1.77 & 0.79 & 24 \\
\hline 1 & 4 & 1 & 1 & 0.84 & 0.16 & 0.92 & 0.09 & 24 \\
\hline 1 & 4 & 1 & 4 & 0.85 & 0.15 & 0.87 & 0.16 & 24 \\
\hline 1 & 4 & 4 & 1 & 0.81 & 0.15 & 1.63 & 0.78 & 24 \\
\hline 1 & 4 & 4 & 4 & 0.84 & 0.16 & 1.72 & 0.89 & 24 \\
\hline 4 & 1 & 1 & 1 & 1.39 & 0.62 & 0.89 & 0.13 & 24 \\
\hline 4 & 1 & 1 & 4 & 1.39 & 0.62 & 0.84 & 0.15 & 24 \\
\hline 4 & 1 & 4 & 1 & 1.34 & 0.64 & 1.53 & 0.75 & 24 \\
\hline 4 & 1 & 4 & 4 & 1.44 & 0.81 & 1.36 & 0.56 & 24 \\
\hline 4 & 4 & 1 & 1 & 1.19 & 0.72 & 0.88 & 0.18 & 24 \\
\hline 4 & 4 & 1 & 4 & 1.33 & 0.71 & 0.82 & 0.20 & 24 \\
\hline 4 & 4 & 4 & 1 & 1.23 & 0.57 & 1.91 & 0.76 & 24 \\
\hline 4 & 4 & 4 & 4 & 1.37 & 0.51 & 1.49 & 0.72 & 24 \\
\hline
\end{tabular}

$K$ is shown for both displays 
Table 8 ANOVA effects in Experiment 4

\begin{tabular}{|c|c|c|c|c|c|c|c|c|}
\hline \multirow[b]{2}{*}{ Effect } & \multicolumn{4}{|c|}{ Display $1 K$} & \multicolumn{4}{|c|}{ Display $2 K$} \\
\hline & $d f$ & Mean Squared Error & $F$ & Partial Eta Squared & $d f$ & Mean Squared Error & $F$ & Partial Eta Squared \\
\hline $\mathrm{D} 1 \mathrm{~T}$ & 1 & 22.46 & $26.82^{* * *}$ & 0.54 & 1 & 0.75 & $7.43^{*}$ & 0.24 \\
\hline Error(D1T) & 23 & 0.84 & & & 23 & 0.10 & & \\
\hline D1D & 1 & 0.49 & $9.54^{* * *}$ & 0.29 & 1 & 0.17 & 0.90 & 0.04 \\
\hline Error(D1D) & 23 & 0.05 & & & 23 & 0.18 & & \\
\hline $\mathrm{D} 2 \mathrm{~T}$ & 1 & 0.00 & 0.02 & 0.00 & 1 & 56.94 & $49.95^{* * * *}$ & 0.68 \\
\hline Error(D2T) & 23 & 0.14 & & & 23 & 1.14 & & \\
\hline $\mathrm{D} 2 \mathrm{D}$ & 1 & 0.35 & 3.00 & 0.12 & 1 & 0.75 & $4.43^{*}$ & 0.16 \\
\hline Error(D2D) & 23 & 0.12 & & & 23 & 0.17 & & \\
\hline $\mathrm{D} 1 \mathrm{~T} \times \mathrm{D} 1 \mathrm{D}$ & 1 & 0.15 & 1.93 & 0.08 & 1 & 0.58 & $7.04^{*}$ & 0.23 \\
\hline Error(D1T×D1D) & 23 & 0.08 & & & 23 & 0.08 & & \\
\hline $\mathrm{D} 1 \mathrm{~T} \times \mathrm{D} 2 \mathrm{~T}$ & 1 & 0.03 & 0.21 & 0.01 & 1 & 0.30 & 3.58 & 0.13 \\
\hline Error(D1T×D2T) & 23 & 0.13 & & & 23 & 0.08 & & \\
\hline $\mathrm{D} 1 \mathrm{D} \times \mathrm{D} 2 \mathrm{~T}$ & 1 & 0.00 & 0.04 & 0.00 & 1 & 0.21 & 1.31 & 0.05 \\
\hline Error(D1D×D2T) & 23 & 0.12 & & & 23 & 0.16 & & \\
\hline $\mathrm{D} 1 \mathrm{~T} \times \mathrm{D} 1 \mathrm{D} \times \mathrm{D} 2 \mathrm{~T}$ & 1 & 0.01 & 0.08 & 0.00 & 1 & 0.76 & $11.38^{* *}$ & 0.33 \\
\hline Error $(\mathrm{D} 1 \mathrm{~T} \times \mathrm{D} 1 \mathrm{D} \times \mathrm{D} 2 \mathrm{~T})$ & 23 & 0.12 & & & 23 & 0.07 & & \\
\hline $\mathrm{D} 1 \mathrm{~T} \times \mathrm{D} 2 \mathrm{D}$ & 1 & 0.11 & 0.87 & 0.04 & 1 & 0.79 & $12.69^{* * *}$ & 0.36 \\
\hline Error(D1T×D2D) & 23 & 0.13 & & & 23 & 0.06 & & \\
\hline $\mathrm{D} 1 \mathrm{D} \times \mathrm{D} 2 \mathrm{D}$ & 1 & 0.03 & 0.41 & 0.02 & 1 & 0.05 & 0.45 & 0.02 \\
\hline Error(D1D×D2D) & 23 & 0.08 & & & 23 & 0.11 & & \\
\hline $\mathrm{D} 1 \mathrm{~T} \times \mathrm{D} 1 \mathrm{D} \times \mathrm{D} 2 \mathrm{D}$ & 1 & 0.07 & 0.83 & 0.03 & 1 & 0.16 & 0.63 & 0.03 \\
\hline Error(D1T×D1D×D2D) & 23 & 0.08 & & & 23 & 0.25 & & \\
\hline $\mathrm{D} 2 \mathrm{~T} \times \mathrm{D} 2 \mathrm{D}$ & 1 & 0.03 & 0.25 & 0.01 & 1 & 0.11 & 0.67 & 0.03 \\
\hline Error(D2T×D2D) & 23 & 0.11 & & & 23 & 0.17 & & \\
\hline $\mathrm{D} 1 \mathrm{~T} \times \mathrm{D} 2 \mathrm{~T} \times \mathrm{D} 2 \mathrm{D}$ & 1 & 0.00 & 0.02 & 0.00 & 1 & 0.72 & $8.95^{* *}$ & 0.28 \\
\hline Error(D1T×D2T×D2D) & 23 & 0.12 & & & 23 & 0.08 & & \\
\hline $\mathrm{D} 1 \mathrm{D} \times \mathrm{D} 2 \mathrm{~T} \times \mathrm{D} 2 \mathrm{D}$ & 1 & 0.02 & 0.15 & 0.01 & 1 & 0.05 & 0.42 & 0.02 \\
\hline Error(D1D×D2T×D2D) & 23 & 0.12 & & & 23 & 0.11 & & \\
\hline $\mathrm{D} 1 \mathrm{~T} \times \mathrm{D} 1 \mathrm{D} \times \mathrm{D} 2 \mathrm{~T} \times \mathrm{D} 2 \mathrm{D}$ & 1 & 0.02 & 0.21 & 0.01 & 1 & 0.13 & 0.62 & 0.03 \\
\hline Error $(\mathrm{D} 1 \mathrm{~T} \times \mathrm{D} 1 \mathrm{D} \times \mathrm{D} 2 \mathrm{~T} \times \mathrm{D} 2 \mathrm{D})$ & 23 & 0.09 & & & 23 & 0.22 & & \\
\hline
\end{tabular}

${ }^{*}$ Significant at $\alpha=.05 .{ }^{* *}$ Significant at $\alpha=.01 .{ }^{* * *}$ Significant at $\alpha=.001$. D1T: Display 1 targets. D1D: Display 1 distractors. D2T: Display 2 targets. D2D: Display 2 distractors. Effects are shown for target report in both displays

\section{References}

Awh, E., \& Jonides, J. (2001). Overlapping mechanisms of attention and spatial working memory. Trends in Cognitive Sciences, 5, 119-126. doi:10.1016/S1364-6613(00)01593-X

Baddeley, A. D. (1993). Working memory or working attention? In A. D. Baddeley \& L. Weiskrantz (Eds.), Attention: Selection, awareness, and control. A tribute to Donald Broadbent (pp. 152-170). New York, NY: Oxford University Press.

Baddeley, A. D., \& Hitch, G. J. (1974). Working memory. In G. H. Bower (Ed.), The psychology of learning and motivation: Advances in research and theory (Vol. 8, pp. 47-89). New York, NY: Academic Press. doi:10.1016/S0079-7421(08)60452-1

Bays, P. M., Catalao, R. F. G., \& Husain, M. (2009). The precision of visual working memory is set by allocation of a shared resource. Journal of Vision, 9(10), 7:1-11. doi:10.1167/9.10.7
Besner, D. (1987). Phonology, lexical access in reading, and articulatory suppression: A critical review. Quarterly Journal of Experimental Psychology, 39, 467-478.

Broadbent, D. E. (1957). A mechanical model for human attention and immediate memory. Psychological Review, 64, 205-215.

Bundesen, C. (1990). A theory of visual attention. Psychological Review, 97, 523-547. doi:10.1037/0033-295X.97.4.523

Bundesen, C. (1998). Visual selective attention: Outlines of a choice model, a race model, and a computational theory. Visual Cognition, 5, 287-309.

Bundesen, C., Pedersen, L. F., \& Larsen, A. (1984). Measuring efficiency of selection from briefly exposed visual displays: A model for partial report. Journal of Experimental Psychology: Human Perception and Performance, 10, 329-339. doi:10.1037/0096-1523.10.3.329

Bundesen, C., Shibuya, H., \& Larsen, A. (1985). Visual selection from multielement displays: A model for partial report. In M. I. Posner \& 
O. S. M. Marin (Eds.), Attention and performance XI: Mechanisms of attention (pp. 631-649). Hillsdale, NJ: Erlbaum.

Chun, M. M. (2011). Visual working memory as visual attention sustained internally over time. Neuropsychologia, 49, 1407-1409.

Cowan, N. (1988). Evolving conceptions of memory storage, selective attention, and their mutual constraints within the human information-processing system. Psychological Bulletin, 104, 163191. doi:10.1037/0033-2909.104.2.163

Cowan, N. (2010). The magical mystery four: How is working memory capacity limited, and why? Current Directions in Psychological Science, 19, 51-57. doi:10.1177/0963721409359277

Duncan, J., Ward, R., \& Shapiro, K. (1994). Direct measurement of attentional dwell time in human vision. Nature, 369, 313-315. doi: $10.1038 / 369313 \mathrm{a} 0$

Engle, R. W. (2002). Working memory capacity as executive attention. Current Directions in Psychological Science, 11, 19-23. doi:10.1111/1467-8721.00160

Eriksen, C. W., \& Collins, J. F. (1969). Temporal course of selective attention. Journal of Experimental Psychology, 80, 254-261. doi: $10.1037 / \mathrm{h} 0027268$

James, W. (1890). The principles of psychology. New York, NY: Henry Holt.

JASP Team. (2016). JASP (Version 0.7.5.5) [Computer software].

Kiyonaga, A., \& Egner, T. (2013). Working memory as internal attention: Toward an integrative account of internal and external selection processes. Psychonomic Bulletin \& Review, 20, 228-242. doi:10.3758/s13423-012-0359-y

Kiyonaga, A., \& Egner, T. (2014a). Resource-sharing between internal maintenance and external selection modulates attentional capture by working memory content. Frontiers in Human Neuroscience, 8(670), 1-9. doi:10.3389/fnhum.2014.00670

Kiyonaga, A., \& Egner, T. (2014b). The working memory Stroop effect: When internal representations clash with external stimuli. Psychological Science, 25, 1619-1629.

Lachter, J., Forster, K. I., \& Ruthruff, E. (2004). Forty-five years after Broadbent (1958): Still no identification without attention. Psychological Review, 111, 880-913. doi:10.1037/0033295X.111.4.880

Logan, G. D. (1976). Converging evidence for automatic perceptual processing in visual search. Canadian Journal of Psychology, 30, 193 200. doi: $10.1037 / \mathrm{h} 0082061$

Logan, G. D. (1978). Attention in character-classification tasks: Evidence for the automaticity of component stages. Journal of Experimental Psychology: General, 107, 32-63. doi:10.1037/0096-3445.107.1.32

Logan, G. D. (1996). The CODE theory of visual attention: An integration of space-based and object-based attention. Psychological Review, 103, 603-649.
Luck, S. J., \& Vogel, E. K. (1997). The capacity of visual working memory for features and conjunctions. Nature, 390, 279-281. doi: $10.1038 / 36846$

Morey, R. D., \& Wagenmakers, E.-J. (2014). Simple relation between Bayesian order-restricted and point-null hypothesis tests. Statistics and Probability Letters, 92, 121-124.

Nosofsky, R. M. (1986). Attention, similarity, and the identification-categorization relationship. Journal of Experimental Psychology: General, 115, 39-57. doi:10.1037/0096-3445.115.1.39

Oberauer, K., \& Lewandowsky, S. (2011). Modeling working memory: A computational implementation of the TimeBased Resource-Sharing theory. Psychonomic Bulletin \& Review, 18, 10-45. doi:10.3758/s13423-010-0020-6

Petersen, A., Kyllingsbæk, S., \& Bundesen, C. (2012). Measuring and modeling attentional dwell time. Psychonomic Bulletin \& Review, 19, 1029-1046.

Pratte, M. S., \& Tong, F. (2014). Spatial specificity of working memory representations in the early visual cortex. Journal of Vision, 14(3), 22:1-12. doi:10.1167/14.3.22

Rouder, J. N., Speckman, P. L., Sun, D., Morey, R. D., \& Iverson, G. (2009). Bayesian $t$ tests for accepting and rejecting the null hypothesis. Psychonomic Bulletin \& Review, 16, 225-237. doi:10.3758 /PBR.16.2.225

Scarborough, D. L. (1972). Memory for brief visual displays of symbols. Cognitive Psychology, 3, 408-429.

Shibuya, H., \& Bundesen, C. (1988). Visual selection from multielement displays: Measuring and modeling effects of exposure duration. Journal of Experimental Psychology: Human Perception and Performance, 14, 591-600.

Sperling, G. (1960). The information available in brief visual presentation. Psychological Monographs: General and Applied, 74(11, Whole No. 498), 1-29.

Theeuwes, J., Godijn, R., \& Pratt, J. (2004). A new estimation of the duration of attentional dwell time. Psychonomic Bulletin \& Review, 11, 60-64.

Vogel, E. K., Woodman, G. F., \& Luck, S. J. (2001). Storage of features, conjunctions, and objects in visual working memory. Journal of Experimental Psychology: Human Perception and Performance, 27, 92-114. doi:10.1037/0096-1523.27.1.92

Woodman, G. F., \& Luck, S. J. (2004). Visual search is slowed when visuospatial working memory is occupied. Psychonomic Bulletin \& Review, 11, 269-274. doi:10.3758/BF03196569

Woodman, G. F., Vogel, E. K., \& Luck, S. J. (2001). Visual search remains efficient when visual working memory is full. Psychological Science, 12, 219-224. doi:10.1111/1467-9280.00339

Zhang, W., \& Luck, S. J. (2008). Discrete fixed-resolution representations in visual working memory. Nature, 453, 233-235. doi:10.1038 /nature 06860 